\title{
Review of Black Carbon in the Arctic-Origin, Measurement Methods, and Observations
}

\author{
Nicole Mölders ${ }^{1,2}$, Stanley G. Edwin ${ }^{1,2}$ \\ ${ }^{1}$ Geophysical Institute, University of Alaska Fairbanks, Fairbanks, USA \\ ${ }^{2}$ Department of Atmospheric Sciences, University of Alaska Fairbanks, Fairbanks, USA \\ Email: cmoelders@alaska.edu
}

How to cite this paper: Mölders, N. and Edwin, S.G. (2018) Review of Black Carbon in the Arctic-Origin, Measurement Methods, and Observations. Open Journal of Air Pollution, 7, 181-213.

https://doi.org/10.4236/ojap.2018.72010

Received: May 31, 2018

Accepted: June 26, 2018

Published: June 29, 2018

Copyright (c) 2018 by authors and Scientific Research Publishing Inc. This work is licensed under the Creative Commons Attribution International License (CC BY 4.0).

http://creativecommons.org/licenses/by/4.0/

(c) (i) Open Access

\begin{abstract}
Current knowledge about black carbon (BC) emission estimates, state-of-the-art measurement methods, near-surface $\mathrm{BC}$ concentrations ([BC]), and mixing ratios in snow is consolidated for the Arctic. Since no direct method exists to measure $[\mathrm{BC}]$, results from modern indirect methods differ among devices. Pan-Arctic wide $[\mathrm{BC}]$ and changes are hard to access; monitoring often ends once national ambient air quality standards are met. Few remote sites have long records. Past measurements showed distinct differences among the various Arctic climate regions. Past and own observations in communities permit qualitative discussion of the diurnal course, response to weather, season, or different emission situations like weekdays and weekends at a given site and/or among sites. Comparison of data from collocated aethalometer indicated more similar accuracy than found in mid- and low-latitudes despite of much lower ambient temperatures and $[\mathrm{BC}]$. Snow samples give an incomplete glimpse at the removal and input into ecosystems.
\end{abstract}

\section{Keywords}

Black Carbon Emissions in the Arctic, Arctic Black Carbon Observations, Measuring Black Carbon in the Arctic, Black Carbon Deposition in the Arctic

\section{Introduction}

In this Millennium, black carbon (BC) in the Arctic has gained huge public interest [1]. In general, BC results from incomplete combustion of carbonaceous fuels. Different fuel types produce different amounts of BC. Natural gas and diesel fuels are on the low and high amount side, respectively. Bottom-up inventory methods estimated the 2000 total global BC emissions to be $7500 \mathrm{Gg} \cdot \mathrm{yr}^{-1}$ with an uncertainty of $2000-29,000 \mathrm{Gg} \cdot \mathrm{yr}^{-1}$ [2]. 
The major concern of the public is the impacts of $\mathrm{BC}$ on the local radiation budget. Numerous studies discussed its direct and indirect impacts on the radiation budget in depth [2] [3] [4] [5]. In the interest of brevity, we renounce repeating them here.

$\mathrm{BC}$ is also long known to affect the water cycle; while $\mathrm{BC}$ alone is insoluble in water, aged BC aerosols can act as cloud and ice nuclei [6]. Consequently, cloud and precipitation formation as well as atmospheric removal processes might change with changing BC concentrations [7]. Changes in cloudiness, cloud-life time, coverage and precipitation again impact the energy cycle via changes in the radiation budget (e.g. [6] [7] and work cited therein).

An aspect of BC, which the public is often unaware of, is its role in the formation of particulate matter (PM), which at sizes less than $2.5 \mu \mathrm{m}$ in diameter $\left(\mathrm{PM}_{2.5}\right)$ is health adverse (e.g. [8] [9] [10] [11] [12]). $\mathrm{PM}_{2.5}$ can enter the lungs, pass thru human skin, and may cause cardiovascular problems, respiratory diseases, and even cancer. For a comprehensive review on the health adverse effects of short and long-term exposure to $\mathrm{PM}_{2.5}$ see [13] [14]; see [15] for a BC impact study on health with focus on the Sub-Arctic.

$\mathrm{PM}$ is a composite of various species which can include $\mathrm{BC}$, elemental carbon (EC) and organic carbon (OC), among other things. $\mathrm{BC}$ and $\mathrm{EC}$ themselves have negligible impacts on human health. However, upon emission, BC particles undergo complex processes with co-emitted OC, toxic semi-volatile organics, inorganic salts from both nitrogen dioxide $\left(\mathrm{NO}_{2}\right)$ and sulfur dioxide $\left(\mathrm{SO}_{2}\right)$, as well as atmospheric water. These species may deposit on hygroscopic carbonaceous particles; also other aerosol components can join $\mathrm{BC}$ during particle growth [6]. This so-called aging process means that a particle rarely is pure $\mathrm{BC}$, and $\mathrm{BC}$ containing aerosols may carry toxic and/or health adverse constituents.

Ambient air samples of BC-aerosol contain up to more than $90 \%$ other constituents. Thus, $\mathrm{BC}$ mass concentration (in $\mathrm{ng} \cdot \mathrm{m}^{-3}$ ) cannot be measured directly by weighing the $\mathrm{BC}$ in an air sample; $\mathrm{BC}$ mass must be determined indirectly by measuring optical, and/or thermal properties of BC. For instance, BC has high sp2-bonded carbon content and Raman spectroscopic responses similar to graphite. The physical relationship between the measured property and the amount of $\mathrm{BC}$ then permits deriving the $\mathrm{BC}$ concentration, hereafter written as $[\mathrm{BC}]$.

Typical atmospheric residence times of BC-containing PM are 4 to 7 days depending on weather conditions; during transport, atmospheric species from emission sources along the way may attach to BC particles [6]. Transport of BC emitted in mid latitudes contributes a substantial fraction to Arctic BC [16] [17] [18] [19].

Recent research showed that air quality in Arctic cities differs not only due to their emissions, size, and the advection of pollutants from downwind regions, but also due to their local climate. Cities located in temperate mesothermal climate according to the Köppen-Geiger classification [20] typically have better air quality than cities in continental microthermal climates [21].

Given the huge variability of $\mathrm{BC}$-containing aerosol, and the fact that the 
chemical composition of PM may affect light-absorbing (soot/BC/EC) and/or may cause light-scattering (organics, inorganics) many different indirect optical measurement techniques and thermal optical analysis methods were developed. Some of them permit continuous, or semi-continuous (online) observations, while others work offline. Those instruments have been successfully applied in mid- and low-latitudes.

As of today, no overall Pan-Arctic comprehensive assessment of BC from emissions to removal exists. Emission inventories and measurements of concentration baselines, however, are pre-requisites to assess impacts from anticipated increases in Arctic shipping on human and ecosystem health as well as subsistence lifestyle. The goal of this paper is to 1) assess Arctic BC emissions; 2) review, evaluate current state-of-the-art $\mathrm{BC}$ measurement methods for Arctic application and consolidate knowledge on past; 3) Arctic BC concentrations at breathing level, 4) BC removal in the Arctic; and 5) identify gaps in knowledge and steps for further investigations. Here, we consider the region north of $59.9 \mathrm{~N}$ as "Arctic".

\section{Black Carbon Emissions}

Often countries report emission data at the state, province, borough or country level. Generally, estimates of $\mathrm{BC}$ emissions base on $\mathrm{PM}_{2.5}$ emissions from combustion processes multiplied by the fraction of $\mathrm{BC}$ in the $\mathrm{PSM}_{2.5}$ for the particular emission source [22]. All eight Arctic countries (Canada, Denmark, Finland, Iceland, Norway, Russia, Sweden, United States) have also territory outside the Arctic. Consequently, assessment of Arctic BC emissions is difficult. In the following, we discuss emission estimates for the Arctic countries at-large, and restrict us to the region north of $59.9 \mathrm{~N}$ when possible.

\subsection{Arctic Emission Sources}

Major Arctic BC-emission sources are shipping [23] [24] [25] [26] [27], boreal wildfires and biomass burning [28]. In the new Millennium, Arctic ship traffic and hence $\mathrm{BC}$ emissions from shipping have seen notable increases due to the long record of, on average, decreasing sea-ice extend, increased last-chance tourism, and shipping of supply for offshore oil/gas extraction activities [1] [29] [30] [31]. Further emission sources for BC are space heating [32], solid fuel based power generation [33], traffic [34], on and off road diesel vehicles [35] [36] [37], and flaring [38] [39]. Small contributions stem from exploratory drilling, fire places, cook stoves, municipal waste-burning, as well as meat and fish smoking by indigenous people. In the European Arctic, sauna stoves are strong contributors to $[\mathrm{BC}]$. In boreal regions, residential wood combustion is a major source of $\mathrm{BC}$ in winter [32].

\subsection{Emission Inventories}

Generally, BC-emission measurements barely exist and lack a common standard. 
Sweden, for instance, measures in stacks, while Denmark, Norway, and Finland apply emission factors based on dilution tunnels. This means available emissions measurements are hard to compare. See [40] [41] for reviews on US and European BC source apportionment studies, and [37] for BC emissions in Russia.

Many emissions inventories only report $\mathrm{PM}_{10}$ and $\mathrm{PM}_{2.5}$ without specification of constituents. Out of the inventories reporting carbon emissions, only few distinguish between EC, OC and BC. Even then, emission estimates differ among inventories due to the assumed partitioning of PM, assumed emission factors, and whether these data are activity based or from reported data. Emissions inventories differ due to the method of creating them (e.g. bottom-up, top-down), their spatial and temporal resolution, and the base-years used [46] [47] [48]. For differences between bottom-up and top-down emissions inventories see [47] [49] [50].

Figure 1 shows exemplarily gridded Arctic BC emission totals for 2008 from different inventories [39] [42] [43] [44] [45]. The Emissions Database for Global Atmospheric Research version 4.1 (EDGARv4.1) is based on worldwide consistent emission and activity factors, while EDGAR-HTAP (Hemispheric Transport of Air Pollution) inserted nationally reported emissions where available.

Discrepancies among emissions inventories occur from 1) different national classifications of BC sources, data collection methods (bottom-up vs. top-down); 2) differences in accounting for sources as point-, area-, or line-sources; and/or 3) lumping of emission sectors. Some inventories lump, for instance, residential and commercial space heating, while others lump residential space heating and power generation as one emissions sector.

Even within an emissions inventory spatial discrepancies of emissions from the same sector may occur due to data reporting requirements prescribed by regional and/or national agencies, and how they allocate (point-, area-, or line-sources) and/or lump data. Figure 2 illustrates the consequences of such agency/law related discrepancies by two examples. Figure 2(a) reveals that in some Canadian provinces, agencies assign BC emissions from off-road transport to the entire province (see purple area), while others assign them to the actual mining area. In the North American Arctic, inland and coastal ship/boat traffic is accounted for as off-road transport. The Yukon, Mackenzie, and the shipping lanes along the coast and into Hudson Bay are clearly visible; some frozen rivers serve as ice roads in winter. On the contrary, Russian and European agencies report $\mathrm{BC}$ release from coastal shipping as ship emissions; the shipping lanes are clearly visible in the annual total emissions shown in Figure 1(a) (mostly green lines). Figure 2(b) illustrates consequences of lumping and spatial allocation. Including space heating into the energy sector makes the emissions of power generation facilities to areal sources. Reporting at county/borough/city levels leads to spatially heterogeneous distribution of emissions (e.g. Scandinavia); reporting at the province/state level leads to more homogeneous, and seemingly low emissions over a large area (e.g. southern part of the Northwest Territories). 


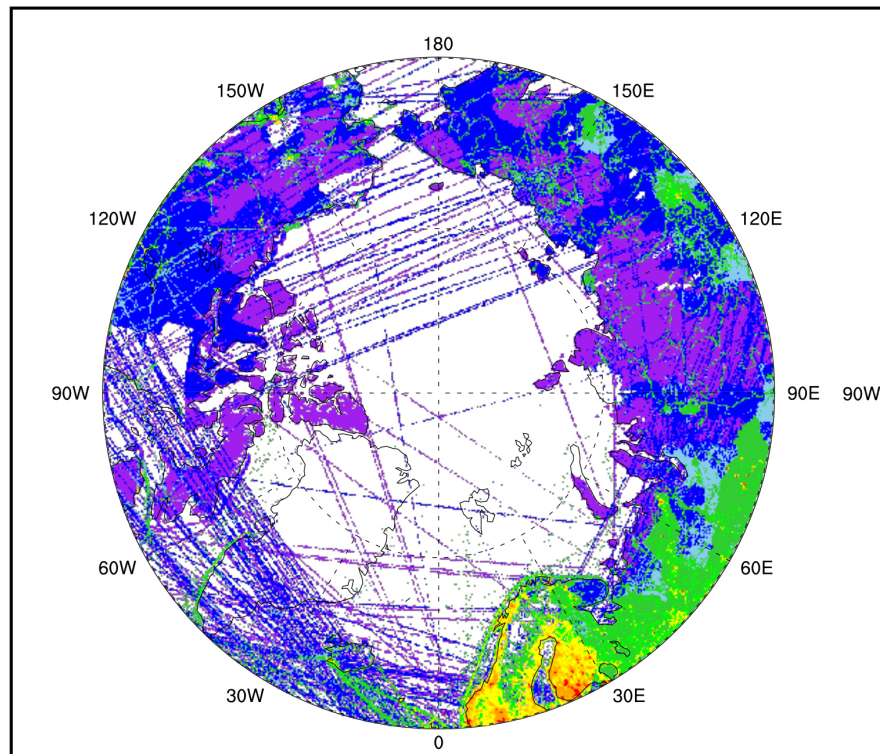

(a)

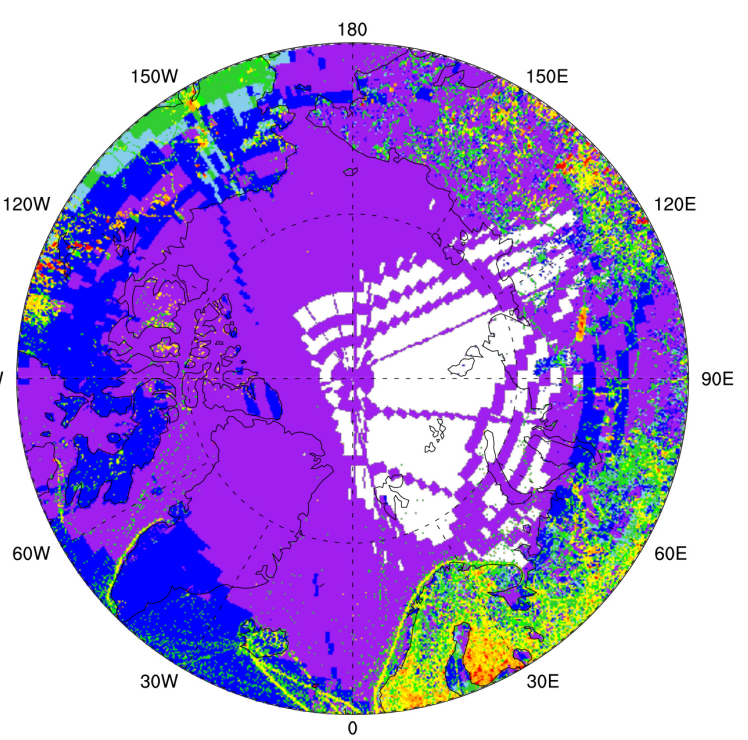

(b)
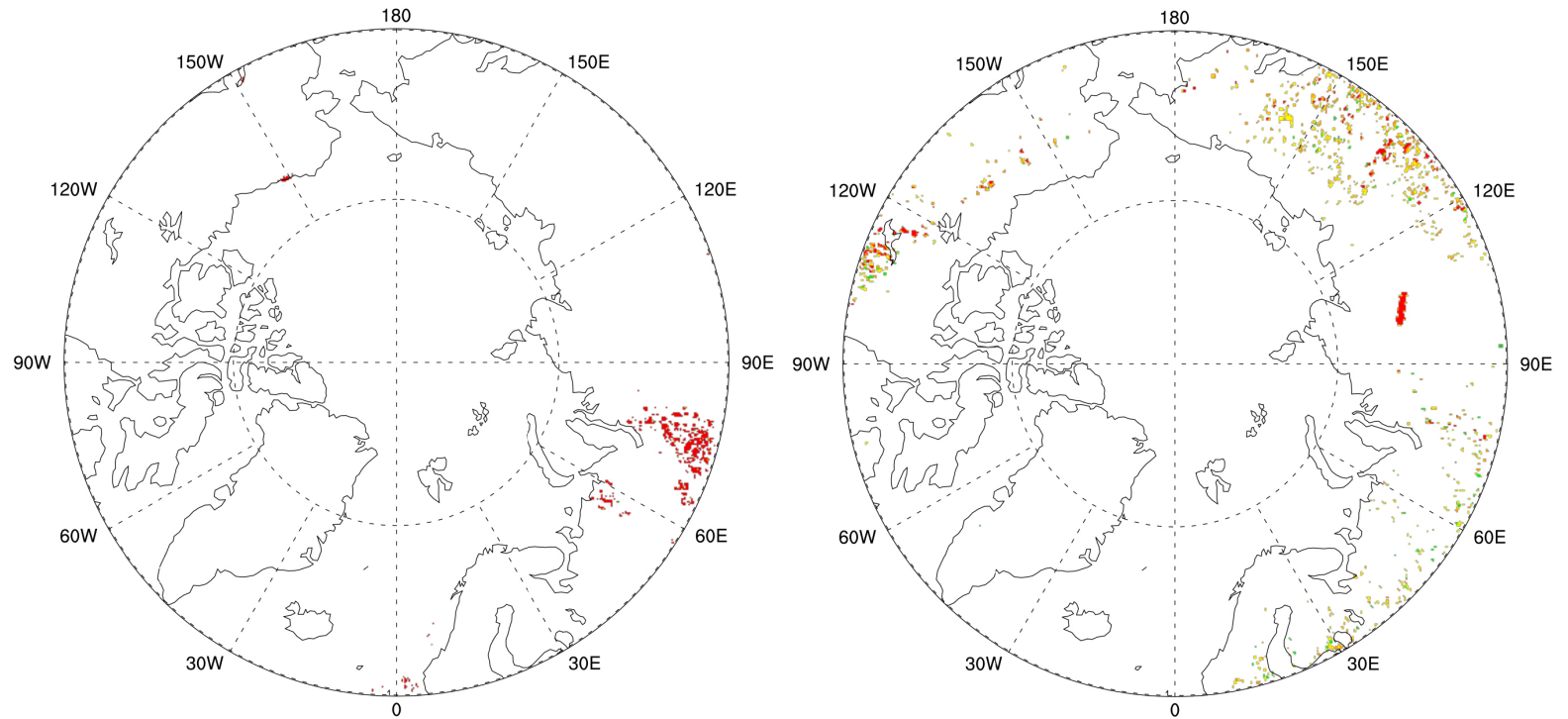

(c)

(d)

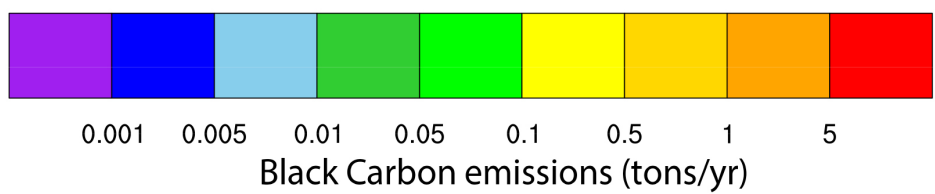

Figure 1. Comparison of 2008 annual total anthropogenic BC emissions except from flares and fires as reported by (a) The EDGAR-HTAP [42], and (b) Technology based [43] emission inventories; 2008 annual total BC emissions from (c) Flares [39], and (d) Fires [44] [45]. Annual emission totals of other years look similar (therefore not shown). One metric ton equals $0.001 \mathrm{Gg}$.

Accounting for emissions over the region instead of at their actual area of occurrence leads to too high emissions everywhere, but too low emissions where they actually occur. Concentration ratios of competing reactants affect various chemical reactions. Thus, reaction products will differ notably if, as in the 


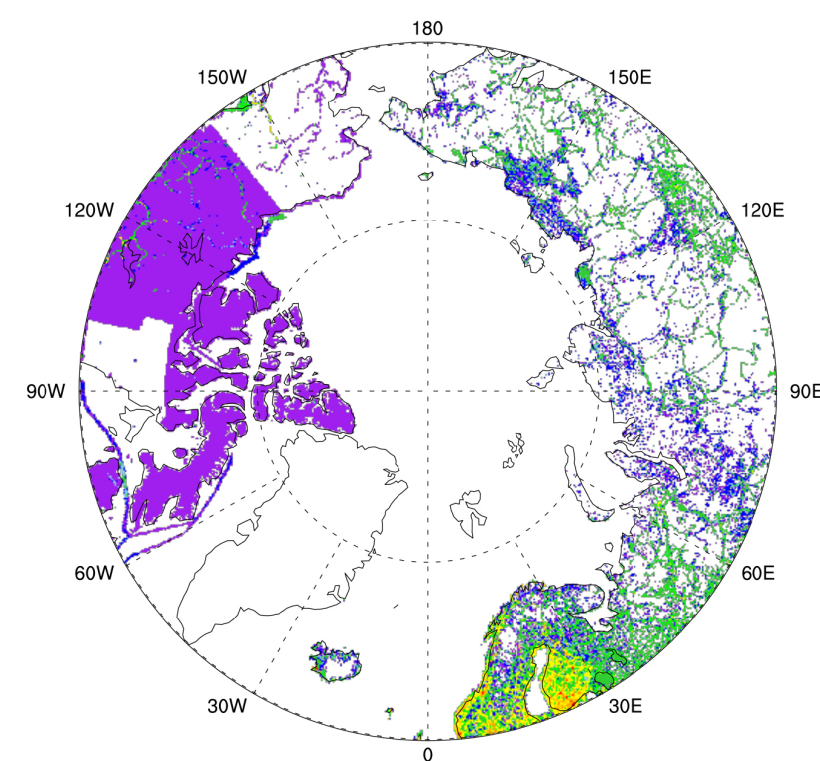

(a)

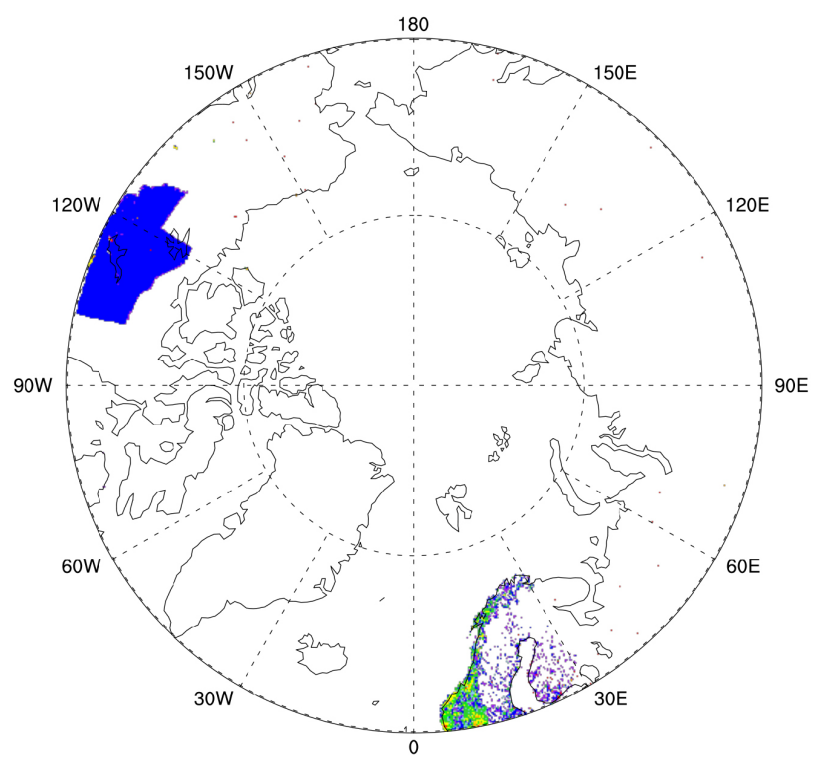

(b)

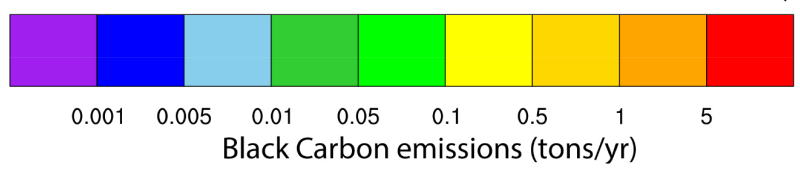

Figure 2. Examples of artifacts in emission inventories due to regional differences in classification, spatial allocation, and lumping of emission sources. Shown are the total 2008 BC emissions associated with (a) Transportation, and (b) The energy sector in the EDGAR-HTAP inventory (Figure 1(a)). Note that similar spatial discrepancies exist for other emissions sectors and emission inventories using reported emissions data (therefore not shown).

example above, the total off-road emissions are equally distributed over the region while the actual real world emissions are released in an open-pit mine. Note that inversions in open-pit mines are a major air quality issue. In case of lumping areal sources like residential/commercial heating with point sources like generation of electrical power, local maxima are smoothed out. Lumping of emission sources also leads to incorrect emission factors and temporal allocations for $n-1$ of the $n$ lumped emission sources.

Besides fuel-type, ship emissions depend on speeds, engine load and size. These factors cause uncertainty in estimated BC emissions from Arctic shipping [51] [52] especially when ships cruise in an area with partial sea-ice occurrence and/or ice-breaking mode. The use of automatic identification system marine traffic data (position, speed, ship characteristics) could improve accuracy of BC ship emissions [52].

Russia's 2010 annual anthropogenic BC emissions were estimated as $223.7 \mathrm{Gg}$ with $81.0,56.0,45.3,29.3$, and $12.1 \mathrm{Gg}$ from gas flaring, residential emissions, transportation, industries, and power plants, respectively [39]. The Evaluating the CLimate and Air Quality ImPacts of ShortlivEd Pollutants version 4.0 (ECLIPSE) reports the 2010 Russian BC emissions from residential heating, transportation, power, industry, and agriculture waste as 22.4, 52.0, 20.6, 5.64 and $24.6 \mathrm{Gg}$, respectively. These inventories differ mainly in their estimates of 
contributions from gas flaring, residential, and industrial emissions. Russia's 2014 anthropogenic BC emissions were estimated at $688 \mathrm{Gg}$ with uncertainty between 401 and $1453 \mathrm{Gg}$; the mean annual total BC emitted by the 2002-2015 wildfires (forests, grasslands, other natural land) and 2003-2009 agricultural burning amounted $569 \mathrm{Gg}(345-790 \mathrm{Gg})$ and $9 \mathrm{Gg}(2-22 \mathrm{Gg})$ [37]. Here the values in brackets give the range of uncertainty. Russian space heating uses raw coal, light brown coal, briquettes, kerosene, residual fuel oil, liquefied petroleum gas, natural and refinery gas, coke-oven coke, firewood, peat, and charcoal [39]. The $2014 \mathrm{BC}$ emissions from this sector and power generation were estimated between 11.9 and $26.7 \mathrm{Gg}$ with a mean of $16.4 \mathrm{Gg}$ [37]. BC emissions from the domestic sector were between 15 and $468 \mathrm{Gg}$ centered at $26.7 \mathrm{Gg}$. The 2010 and $2014 \mathrm{BC}$ emissions from other stationary sources were estimated at $238.1 \mathrm{Gg}$ and 192.2 Gg, respectively. BC emissions from industry were $5.2 \mathrm{Gg}$ with huge uncertainty (1.0 - 51.3 Gg) [37]. Estimates of total BC emissions in Russia due to transportation (diesel and gasoline vehicles, railroad, ships) range from $16.3 \mathrm{Gg}$ to $41.2 \mathrm{Gg}$ with a mean of $29.8 \mathrm{Gg}$ [37]. For a comprehensive discussion of Russian BC emissions uncertainties see [39].

According to Swedish government reports [53], their total annual BC emissions were $4.81 \mathrm{Gg}, 5.1 \mathrm{Gg}, 4.2 \mathrm{Gg}$ and $3.67 \mathrm{Gg}$ in 2000, 2005, 2012, and 2013, respectively. Industrial processes, road traffic, off-road vehicles, energy sectors, and residential biomass burning contributed about $0.210 \mathrm{Gg}, 0.714 \mathrm{Gg}, 0.756 \mathrm{Gg}$, $0.798 \mathrm{Gg}$, and $1.134 \mathrm{Gg}$ in 2012 .

The same source lists the Norwegian total annual BC emissions at $5.1 \mathrm{Gg}$ in 2011. Wood stoves are the primary device for space heating with $1.581 \mathrm{Gg}$. National shipping, diesel vehicles, and the transport sector contributed about 0.867 , 2.04, and $3.06 \mathrm{Gg}$. In the Norwegian Barents region, $\mathrm{BC}$ emissions were about $0.408 \mathrm{Gg}$ [53].

In the Finish Barents region, $\mathrm{BC}$ emissions were about $0.77 \mathrm{Gg}$. The total annual mean Finish BC emissions were $6.46 \mathrm{Gg}$. Besides boilers and stoves, masonry heaters and sauna stoves are common in Finland [53].

In Canada, $\mathrm{BC}$ emissions are calculated using $\mathrm{PM}_{2.5}$ emissions and $\mathrm{BC} / \mathrm{PM}_{2.5}$ ratios. In 2015, they were assessed as $38 \mathrm{Gg}$ [54].

Many emission inventories lack BC emissions from flaring. These emissions depend on the gas flared (e.g. ethane, propane), its fraction of heavy hydrocarbons, its purity, flare size, and velocity across the flare tip [37] [39]. Hydrocarbons can cause soot; impurities cause incomplete combustion. Flare gases with higher energy content than methane produce more BC. Russian flares are larger than Alaska flares. In recent years, flaring declined in Russia. In 2014, BC emissions from flaring in Russia were between 10 and $54 \mathrm{Gg}$ centered at $32 \mathrm{Gg}$ [37].

Appreciable differences in total wildfire BC emissions exist among years depending on the severity of the wildfire season, type of land-cover and area burned [45]. Boreal fires, for instance, can emit BC from the belowground organic layer (e.g. peat, moss, lichen), litter layer, and the forest; black spruce BC 
emissions differ from white spruce, larch, birch or alder. The Global Fire Emissions Database version 3s (GFED3s), for instance, reported the 2000 biogenic BC emissions north of $60 \mathrm{~N}$ in Alaska as $50.414 \mathrm{Gg}$; GFED4s reports BC emissions from North American, Asian and Finnish boreal forest fires as $0.5 \mathrm{Gg}$ [45].

\section{Measuring Near-Surface Black Carbon Concentrations}

As of today, no standardized method to measure [BC] exists [13] [55] [56]. [BC] are operationally defined as the light absorbing and thermal refractory fraction of carbonaceous aerosol, respectively [57]. Health and atmospheric scientists applied aethalometers, particle soot absorption photometers (PSAP), single particle soot photometers (SPS), Continuous Light Absorption Photometers (CLAP), Integrating Spheres (IS), Hybrid Integrating Plate Systems (HIPS), Multi-Angle Absorption Photometers (MAAP), continuous soot-monitoring systems (COSMOS), thermal desorption techniques, and acoustic detection. Not all of these devices have been applied in the Arctic.

Data from these instruments are hard to compare. Results from thermal desorption techniques depend on the applied protocol. All filter-based instruments provide time-integrated values for the chosen sampling interval, which may differ among sites. Unit-to-unit variability can reach up to $30 \%$ for PSAPs and aethalometer, and is lowest $(<5 \%)$ for MAAP; PSAP and MAAP have lower instrument noise than aethalometer. Sources of systematic errors differ among instrumental designs; inlets may cutoff particle size at different diameters [58].

Light scattering by accumulated particles affects all filter-based absorption photometers (e.g. aethalometers, PSAP, CLAP, SPS, HIPS, MAAP). These effects are (incorrectly) termed apparent absorption. Their impact on light transmission causes overestimated absorption. Often empirical factors serve to correct for these effects reducing uncertainty to $20 \%-30 \%$ for the PSAP, IS, HIPS, and aethalometers, and $12 \%$ for the MAAP [59] in labs and/or outside the Arctic. Uncertainty also exists due to electronic noise, instrument variability, and calibration. Optical interaction between particles and filter matrix may yield positive bias for uncorrected filter-based measurements; otherwise, bias can be positive or negative [2].

Brown carbon and dust influence absorption at the same wavelengths as BC. Aging of $\mathrm{BC}$ alters the absorption properties of $\mathrm{BC}$-containing aerosol. Increasing coating of $\mathrm{BC}$ enhances particle size and causes uncertainty in the mass attenuation cross section (MAC) [16]. The bias in optical measurements of [BC], equivalent black carbon mass concentrations ([EBC]) and [EC] caused by coating material depends on the wavelength used; typically $630 \mathrm{~nm}$ is least affected except for high dust concentrations [2]. Unfortunately, dust concentrations are often high in the North American Arctic due to unpaved roads and non-managed rivers [21].

Uncertainty in $[\mathrm{EBC}]$ is about 36\% for aethalometer in the Arctic, 28\% (Arctic haze) to $80 \%$ (summer) for thermal desorption techniques, $28 \%-40 \%$ for SPSs, and $10 \%-20 \%$ for PSAP [16]. 
In the following, we elucidate the principles of 1) filter-based absorption instruments exemplarily by the aethalometer, briefly describe; 2) thermal desorption techniques; 3) acoustic detection; 4) summarize results from instrument comparisons; and 5) evaluate the suitability of these methods for Arctic applications.

\subsection{Aethalometer}

Aethalometer use optical absorption for in-situ (online) EBC detection. They sample ambient air with typical flow rates of $\sim 6.7$ liter. $\mathrm{min}^{-1}$. At high flow rates $\left(>3.5\right.$ liter $\left.\cdot \mathrm{min}^{-1}\right)$, diffusion losses remain below $4 \%$. Non-size specific inlets permit sampling the total aerosol-size distribution during fog periods. In the Arctic, typically, a snow-hood and stainless steel-duct inlet are used. The sampled air should reach laboratory temperature $\left(\sim 21^{\circ} \mathrm{C}\right)$ prior to entering the actual measurement device to ensure relative humidity is less than $20 \%$ [57].

Particles accumulate over a given time interval (e.g. $5 \mathrm{~min}$ ) on a quartz fiber filter. A light source illuminates the sample and a blank filter on one side. On the other side, detectors measure real-time attenuation of light transmitted through the two filters. Typical operational effective wavelengths are 370, 470, 520, 590, 660, 880, and $950 \mathrm{~nm}$. Multispectral (370 - $950 \mathrm{~nm}$ ) absorption coefficients can give information about the chemical composition.

The sample attenuation is

$$
A T N=-\ln \left(\frac{I_{s}}{I_{r}}\right)
$$

where $I_{s}$ and $I_{r}$ are the light transmitted through the sample and blank reference, respectively. Their ratio is the filter transmittance, $\tau$. The temporal change in attenuation is proportional to the attenuation coefficient

$$
\sigma_{A T N}:=-\frac{A}{Q} \frac{\Delta A T N}{\Delta t}
$$

Here, $A, Q$, and $\Delta t$ are the filter spot size area $\left(\mathrm{m}^{2}\right)$, sample flow rate $\left(\mathrm{m}^{3} \cdot \mathrm{s}^{-1}\right)$, and time between light intensity measurements (collection time). The attenuation coefficient depends on the cross-section of light interactions with the collected particles.

The filter spot must advance to a clean filter spot after 2 to 5 min of sampling to avoid that transmission drops too much. This time span is the inner data processing cycle. The internal software provides a temporal mean at the end of this cycle. When collection time is set to values above an aethalometer's upper time limit of the inner cycle, sampling occurs on various spots; data are averaged at the end of the set collection time. This so-called boxcar averaging increases the detection limit with one over the square root of the sampling time at the cost of temporal resolution. Best practice is to sample at the upper limit, and perform post-processing offline as needed for improved signal-to-noise ratio.

Despite aethalometer measure $\sigma_{A T N}$, the output is [EBC]. Equivalent black 
carbon encompasses $\mathrm{BC}$ plus other light-absorbing material. To convert $\sigma_{A T N}$ to $[\mathrm{EBC}]$ a wavelength-dependent mass-specific absorption coefficient or short specific absorption coefficient $\sigma_{a p}\left(\mathrm{~m}^{2} \cdot \mathrm{g}^{-1}\right)$ is used. It is defined as absorption per mass concentration. The aethalometer mass-specific absorption coefficient relates optical attenuation through the filter with equivalent black carbon mass concentration,

$$
[\mathrm{EBC}]=-\frac{\sigma_{A T N}}{\sigma_{a p}}
$$

Typically, the specific absorption coefficient is based on calibrations and theoretical calculations performed during instrument development. The recommended conversion for the Magee aethalometer, for instance, is $\sigma_{a p}=$ $14625 / \lambda$. This value corresponds to $39.5,31.1,28.1,24.8,22.2,16.6$ and 15.4 $\mathrm{m}^{2} \cdot \mathrm{g}^{-1} \mathrm{EBC}$ at $\lambda=370,470,520,590,660,880$, and $950 \mathrm{~nm}$, respectively.

Figure 3 shows data collected at College, Alaska $(64.8594 \mathrm{~N}, 147.8508 \mathrm{~W})$ between September 11 and October 30, 2017 at 370 and $880 \mathrm{~nm}$. The aethalometer pulled air from a parking lot behind the International Arctic Research Center. [EBC] maximum, mean, standard deviation, skewness and kurtosis were 65.9 $\mathrm{ng} \cdot \mathrm{m}^{-3}, 6.0 \pm 6.2 \mathrm{ng} \cdot \mathrm{m}^{-3}, 2.1$, and 7.0 at $370 \mathrm{~nm}$, and $137.3 \mathrm{ng} \cdot \mathrm{m}^{-3}, 12.3 \pm 12.5$ $\mathrm{ng} \cdot \mathrm{m}^{-3}, 2.2$, and 8.1 , at $880 \mathrm{~nm}$. Data correlation between the two channels was $88 \%$ (0.936). The much higher kurtosis than 3 indicates that the size distribution was non-Gaussian and outliers occurred more frequently for high concentrations than in a normal distribution. The spread in the scatter plot of measurements at $370 \mathrm{~nm}$ and $880 \mathrm{~nm}$ (Figure 3) indicates the presence of cofounding aerosol at increasing concentrations.

Besides wavelength, the specific absorption coefficient depends, among other things, on season, filter interaction, environment, and filter loading effects related to particle aging. Values of $\sigma_{a p}$ range from 5 to $20 \mathrm{~m}^{2} \cdot \mathrm{g}^{-1}$, but are constant for a given atmospheric environment [60]. During the 1989 to 2007 [EBC] measurements at Alert, Canada $(82.45083 \mathrm{~N}, 62.34167 \mathrm{~W})$, for instance, the manufacturer-recommended conversion factor of $\sigma_{a p}=19 \mathrm{~m}^{2} \cdot \mathrm{g}^{-1}$ was applied [61]. Multiplication of aethalometer data with the applied conversion factor and dividing by a conversion factor $X$ permits using $X$ instead. See [62] [63] for comprehensive reviews of absorption coefficient measurements.

\section{Quality Assurance/Quality Control}

Even though all scientists apply quality assurance/quality control (QA/QC) and flag data following their national agency's requirements, no Pan-Arctic standardized method exists for flagging BC data. The same is true for corrections related from scattering. Particles in the upper layers of a sample scatter the light beam. The reduced beam diminishes absorption in deeper layers, and [EBC] is underestimated. The manufacturer recommended attenuation coefficient, $\sigma_{a p}$ accounts for this shadowing effect at low to moderate filter loads. At high filter loads, optical measurements of light absorption require additional corrections [61]. 


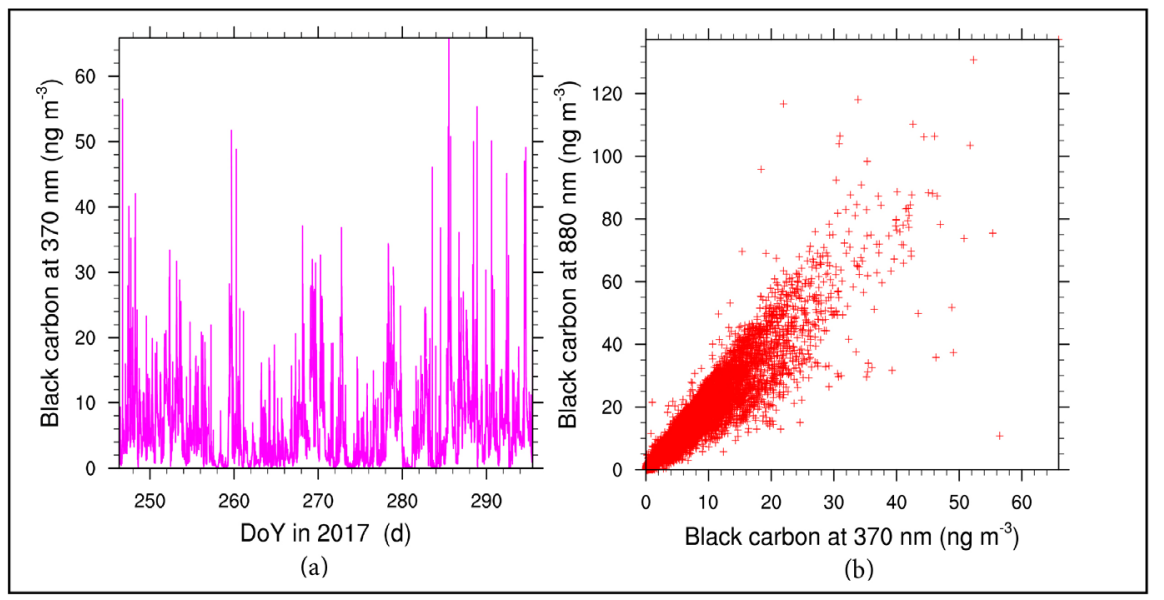

Figure 3. Black carbon concentrations derived from aethalometer measurements at College, Alaska between September 11 and October 30, 2017. (a) Temporal evolution of 5-min mean [EBC]. Data for $880 \mathrm{~nm}$ look similar (therefore not shown), but are higher than at $370 \mathrm{~nm}$. (b) Scatter plot of 5-min mean [EBC] as obtained at 370 and $880 \mathrm{~nm}$.

High values of the filter-loading parameter in the infrared indicate EBC of local sources, while low filter-loading parameters indicate aged $\mathrm{BC}$ coated by ammonium sulfate and/or secondary organics during long-range transport. This means the filter-loading effect can provide a proxy for particle coating, and differentiation between local/fresh and transported/aged particles [64].

Various empirical correction methods exist to calculate the absorption coefficient, $\sigma_{a p}$ from the attenuation coefficient, $\sigma_{A T N}$ [65]. A simple approach derived from observations at three Finnish sites is [65].

$$
[\mathrm{EBC}]_{c o r}=(1+k \cdot A T N) \cdot[\mathrm{EBC}]_{n o n}
$$

where $[\mathrm{EBC}]_{c o r}$, and $[\mathrm{EBC}]_{\text {non }}$ are the corrected and non-corrected $[\mathrm{EBC}]$, and $k$ is the shadowing correction aka aethalometer-correction factor. Negative $k$-values mean overestimation of $[\mathrm{EBC}]$ by $[\mathrm{EBC}]_{n o n}$. At the three Finnish sites, $k$ varied between 0 and 0.015 with a mean of 0.0018 [65].

Unfortunately, $k$-values vary seasonally because of higher EBC to total aerosol ratios in winter than summer; in summer, $k$ depends on wavelength. Correction factors also differ with filter type. At Kevo, Finland (69.75N, 27.033E), for instance, $k=0.025$ and $k=0.0021$ were found for Whatman- 42 and glass-fiber filters, respectively [61]. In the European Arctic, annual shadowing correction is around 20\% [61].

In laboratory studies, aethalometers have shown notable drift on timescales from hours to days. Unfortunately, magnitudes of drift differ among instruments. To determine instrument drift in the field, an absolute filter could serve to capture pressure changes in the sampling line relative to changes in ambient pressure, and relative humidity on a pristine filter. This method might be applicable also to loaded filters of various loadings. Drift testing for $24 \mathrm{~h}$ or more on a pristine filter minimizes influences from semi-volatile species; the absolute filter 
may itself impact the sample. Uncertainty due to in-field drift found for five instruments in the Arctic was about $0.01-0.1 \mathrm{Mm}^{-1}$.

Measurements of $[\mathrm{BC}]$ are challenging. $\mathrm{BC}$ varies highly at high altitude as well as in coastal and Polar Regions. During clean periods, concentrations can be below the detection limit. Post-processing methods serve to increase the signal-to-noise ratio. They lower the detection limit at the cost of temporal resolution. Most often boxcar averaging [66] is applied. The averaging time varies among instruments, and sometimes with application. In aethalometer applications, for instance, the typical averaging time is $5 \mathrm{~min}$.

Some data-processing methods are instrument specific. To keep temporal resolution as high as possible, some scientists use the aethalometer equation and a temporal attenuation change threshold; post-processing only occurs when the threshold is exceeded [67]. This method known as Optimized Noise-reduction Averaging (ONA) expands (reduces) averaging windows at low (high) filter loads. In contrast to the boxcar averaging, the temporal resolution at high aerosol concentrations is barely affected; temporal resolution is only low at small concentrations. ONA permits displaying notable trends at minimum distortion. Applying an attenuation-threshold criterion, aethalometer were able to detect attenuation > $2.1-6.7 \mathrm{Mm}^{-1}$ at six Arctic sites in 2012 to 2014 .

Figure 4 exemplarily shows the mean diurnal course of 5-min [EBC] averaged over the aforementioned 50-d period. The means reveal peaks around noon and at night that correspond to lunch break and the nighttime inversion that frequently builds in the shoulder season. The differences indicate coated BC. For the 50-d period, hourly means of $[\mathrm{EBC}]_{370 \mathrm{~nm}}$ and $[\mathrm{EBC}]_{880 \mathrm{~nm}}$ correlated $90 \%(\mathrm{R}=$ $0.949)$; daily means of $[\mathrm{EBC}]_{370 \mathrm{~nm}}$ and $[\mathrm{EBC}]_{880 \mathrm{~nm}}$ correlated $63 \%(\mathrm{R}=0.795)$. Correlations of 5 -min means at 370 and $880 \mathrm{~nm}$ were $88 \%, 89 \%$ and $88 \%$ over the entire period, on weekdays, and weekends, respectively (Table 1).

On week days, $[\mathrm{EBC}]$ were higher during the day and lower during the night than for these times on weekends (Figure 4). Overall, weekdays saw lower 5-min means than weekends. Differences between $[\mathrm{EBC}]_{370 \mathrm{~nm}}$ and $[\mathrm{EBC}]_{880 \mathrm{~nm}}$ were greater on weekdays, while variance was largest on weekends. These differences can be explained by the different traffic patterns and heating behaviors on weekdays and weekends. On weekends and on weekdays in the evening, households with furnace and woodstove prefer using the less expensive wood instead of heating fuel. The higher than 3 kurtosis (Table 1) indicated that the size distribution approached zero frequency slower than a Gaussian normal distribution meaning more outliers. The distribution was skewed towards few, but large BC particles. Skewness on weekdays and weekends barely differed indicating similar co-founders for the College site.

Similar was found, for instance, for September-October data collected at Tiksi (Russia 71.633N, 128.867E) in 2010 (Table 1). Despite Tiksi's population was only 5063 at that time, its [EBC] was about six times higher than at College. At Tiksi, ship emissions in port and along the shore of the Buor-Khaya Gulf of the Laptev Sea contribute to the $[\mathrm{BC}]$. 


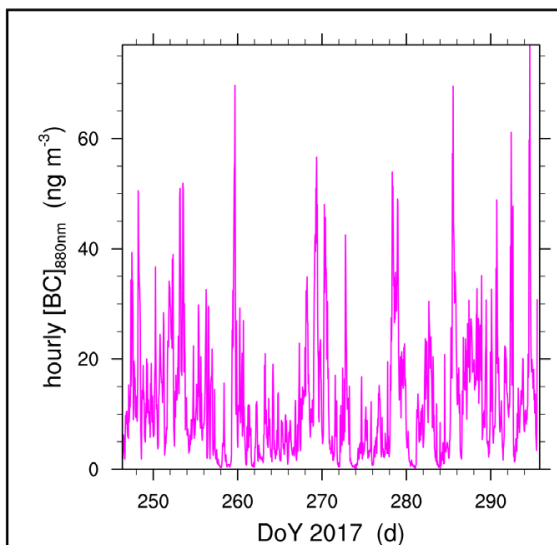

(a)

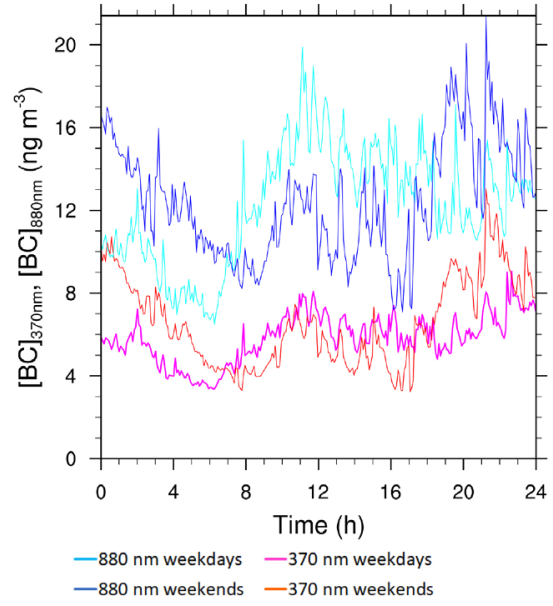

(c)

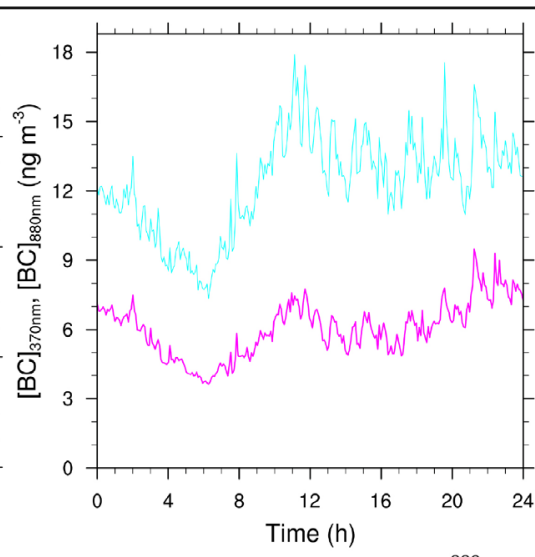

(b) $\quad-880 \mathrm{~nm}$

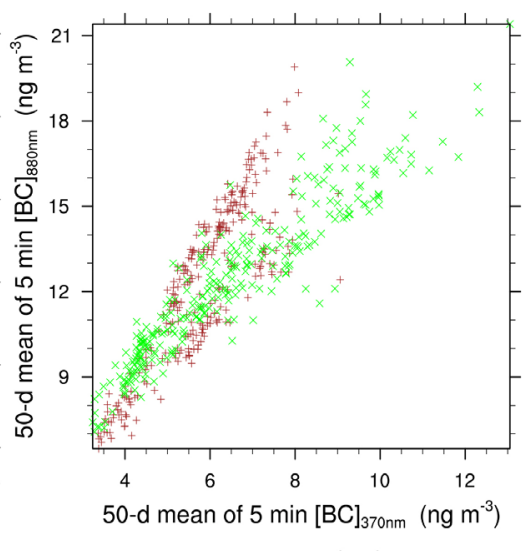

+ weekdays $x$ weekends

(d)

Figure 4. Examples of offline post-processing of observations at College, Alaska. (a) Timeseries of hourly means of [EBC] for a 50-d period from September 11 to October 30, 2017 shown at $880 \mathrm{~nm}$, (b) 50-d mean diurnal course of [EBC] at 370 and $880 \mathrm{~nm}$, (c) Mean diurnal course of [EBC] averaged over all weekdays and weekends of the 50 -d period both at 370 and $880 \mathrm{~nm}$, (d) Period averaged 5-min means of [EBC] at $370 \mathrm{~nm}$ vs. $880 \mathrm{~nm}$ on weekdays and weekends.

\subsection{Other Photometers (PSAP, CLAP, COSMOS, MAAP)}

Like the aethalometer, PSAP and CLAP instruments measure transmission of light through a light-diffusing filter while particles accumulate on the filter [68] at various wavelengths (467 to $660 \mathrm{~nm}$ ). The optical designs are quite similar. Silicon photodiodes measure the intensity of diffuse light transmitted through the sample spots $\left(I_{s}\right)$ and clean (non-sampled) area $\left(I_{r}\right)$ of the filter.

Both PSAP and CLAP typically use E70-2075W filters. Solenoid valves advance to the next sample spot once filter transmittance reaches 0.7. The PSAP uses a single sample spot on a 10-mm filter. The CLAP has two reference clean filter spots and eight sample filter spots on a $47-\mathrm{mm}$ filter. This eight-spot design permits the CLAP to run at ideal conditions $(\tau<0.7)$ eight times as long as the single-spot PSAP making the CLAP more suitable for remote Arctic sites. 
Table 1. September to October statistics for selected [BC] mean 5-min values derived from aethalometer measurements in the Arctic. $\mathrm{R}^{2}, \mathrm{R}, \mathrm{Max}$, and StDev are the correlation between between 5 -min $[\mathrm{BC}]_{370 \mathrm{~nm}}$ and $[\mathrm{BC}]_{880 \mathrm{~nm}}$ in percent, correlation coefficient, maximum concentration and the standard deviation for the respective sites. Regular and Italic values are at $370 \mathrm{~nm}$ and $880 \mathrm{~nm}$, respectively. Data for Tiksi are 2010, College 2017.

\begin{tabular}{ccccccc}
\hline \multirow{2}{*}{ Site } & \multicolumn{5}{c}{ Correlations, extreme values, means and higher moments } \\
\cline { 2 - 7 } & $\mathrm{R}^{2} \%$ & $\mathrm{R}$ & $\begin{array}{c}\text { Max } \\
\mathrm{ng} \cdot \mathrm{m}^{-3}\end{array}$ & $\begin{array}{c}\text { Mean, StDev } \\
\mathrm{ng} \cdot \mathrm{m}^{-3}\end{array}$ & Skewness & Kurtosis \\
\hline \multirow{2}{*}{ College, Alaska } & $88 \%$ & \multirow{2}{*}{0.936} & 65.9 & $6.0 \pm 6.2$ & 2.1 & 7.0 \\
& & & 137.3 & $12.3 \pm 12.5$ & 2.2 & 8.1 \\
Week days & \multirow{2}{*}{$89 \%$} & \multirow{2}{*}{0.942} & 65.9 & $5.8 \pm 5.8$ & 2.1 & 7.8 \\
& & & 51.7 & $6.5 \pm 7.0$ & 1.9 & 5.1 \\
Weekends & \multirow{2}{*}{$88 \%$} & \multirow{2}{*}{0.938} & 137.3 & $12.3 \pm 12.5$ & 2.3 & 9.0 \\
& & & 103.5 & $12.4 \pm 12.6$ & 1.9 & 5.9 \\
Tiksi, Russia & $71 \%$ & \multirow{2}{*}{0.844} & 512.0 & $36.3 \pm 46$ & 4.2 & 24.9 \\
& & & 609.0 & $39.4 \pm 49.2$ & 4.6 & 33.3 \\
Week days & $76 \%$ & \multirow{2}{*}{0.874} & 512 & $32.3 \pm 42.0$ & 4.6 & 30.5 \\
& & & 511 & $45.8 \pm 53.2$ & 3.6 & 17.5 \\
Weekends & \multirow{2}{*}{$64 \%$} & \multirow{2}{*}{0.801} & 597 & $37.3 \pm 48.9$ & 4.7 & 33.5 \\
& & & 609 & $44.2 \pm 49.4$ & 4.5 & 33.8 \\
\hline
\end{tabular}

Typical flow rates and averaging times are $0.5-1$ liter $\cdot \mathrm{min}^{-1}$ and $3 \mathrm{~s}^{-1}$, respectively. The response depends on PM size and cross-sensitivity to particle scattering, which can be measured simultaneously by a nephelometer.

Redistributed liquid-like OC can cause bias as it affects light scattering and absorption. Bias in PSAP absorption coefficients can reach up to $50 \%-80 \%$ at high (15 - 20) organic aerosol to BC ratios [2]. Non-absorbing aerosols and suspended particles can yield overestimates of absorption at $550 \mathrm{~nm}$ of about $20 \%-30 \%$ that can be corrected for [69].

In contrast to PSAP and/or CLAP, COSMOS samples ambient air thru a heated inlet. The heat removes most of the volatile aerosol components prior to particle accumulation on the filter [70]. Charring of low volatility organic species may cause bias in COSMO measurements.

The MAAP is the only real-time absorption photometer that corrects for artifacts from scattering by its design. It namely measures both the radiation transmitted through and scattered back from particles on a glass-fiber tape, and irradiation at various detection angles. Doing so, determines radiation fields in forward and backward direction and permits correction for enhanced absorption by filter loading, back- and multiple-scattering by PM and the filter matrix. A two-stream radiative transfer model calculates the absorption coefficient $\sigma_{A T N}$. MAAPs typically sample with a flow rate of 16.7 liter $\cdot \mathrm{min}^{-1}$.

Mass-specific absorption coefficient $\sigma_{a p}$ can be determined by dividing the MAAP absorption coefficient by the [EC] obtained from co-located thermal methods; at $550 \mathrm{~nm}$ and $670 \mathrm{~nm}$, for instance, the recommended specific absorption coefficients are $8 \mathrm{~m}^{2} \cdot \mathrm{g}^{-1}$ and $6.5 \mathrm{~m}^{2} \cdot \mathrm{g}^{-1}$, respectively [55].

The manufacturer specified MAAP minimum detection limit is $<0.1 \mu \mathrm{g} \cdot \mathrm{m}^{-3}$ 
for 2-min sampling times. Organic carbon can modify particle morphology, which causes bias.

Absolute uncertainty of PSAP and MAAP measurements are typically 0.02 and $0.06 \mathrm{Mm}^{-1}$ for 5-min averages [71]. The MAAP seems to be less prone to interpret light scattering $\left(\sigma_{s p}\right)$ as light absorption than a PSAP or aethalometer.

\subsection{Thermal Techniques}

The SPS uses laser-induced incandescence, i.e. visible thermal radiation to detect the refractory $\mathrm{BC}(\mathrm{rBC})$ mass of individual particles. An IR intra-cavity laser heats individual particles to vaporization temperature (about $400^{\circ} \mathrm{C}$ ). The SPS permits continuous, real-time observation of $\mathrm{rBC}$ over a wide range of concentrations. Calibration to ambient $\mathrm{rBC}$ material is the major cause of bias. Limitation of the size range may add uncertainty. In remote areas, the SPS captures the size range, i.e. most of the $\mathrm{rBC}$ mass and about $50 \%$ of the $\mathrm{rBC}$ number [2]. The SPS may fail to detect particles less than $160 \mathrm{~nm}$ in diameter.

Several thermal desorption techniques exist. All of them are offline. They measure total OC, as they fail to distinguish between organic material (e.g. pollen, spores, yeasts) and primary emitted combustion-related OC aerosol.

The most common thermal methods for $\mathrm{BC}-\mathrm{OC}$ separation use that $\mathrm{BC}$ is non-volatile while $\mathrm{OC}$ is volatile. First, the sample filter is heated in helium gas to volatilize $\mathrm{OC}$ at temperatures $\leq 550^{\circ} \mathrm{C}$. Some protocols ask for a cooling time thereafter. Next the sample is heated in a $98 \%$ helium, $2 \%$ oxygen $\left(\mathrm{O}_{2}\right)$ mix to $\geq$ $550^{\circ} \mathrm{C}$. IR absorption or flame ionization serves to detect carbon dioxide or methane formed from the released gases [2].

Overestimates of [EC] may occur when some OC undergoes pyrolysis or charring, which convert $\mathrm{OC}$ to EC at high temperatures [2]. Further uncertainty exists from 1) interpreting OC as EC, or vice versa, 2) sample compounds retarding OC volatilization, or 3) sample compounds facilitating EC release.

Obviously, analytical results are an operational definition depending on the measurement protocol. Any data comparison would require using the same protocol at all sites. Unfortunately, used protocols differ by temperature ramping, correcting for OC charring during pyrolysis, and sample treatment. In the VDI 2465/1 protocol, for instance, filter samples reside for $24 \mathrm{~h}$ in a 1:1 mixture of toluene and 2-propanol to extract OC. After drying, filters are heated for 1 $\min$ at $200^{\circ} \mathrm{C}$ and $7 \mathrm{~min}$ at $500^{\circ} \mathrm{C}$. Carbon evolving during this process counts as non-extractable $\mathrm{OC}$. Combustion at $650^{\circ} \mathrm{C}$ in an $\mathrm{O}_{2}$ atmosphere provides the [EC]. Minimum detectable carbon mass loading is $9 \mu \mathrm{g}$ C. The scientific community has started a discussion on a standardized thermal-optical protocol for measuring OC and EC [72].

Some thermal methods monitor the optical reflectance of the sample filter [2] to correct for charring and pyrolysis effects. Thermal optical reflectance (TOR) or thermal optical transmittance (TOT) methods provide apparent elemental carbon $\left(\mathrm{EC}_{\mathrm{a}}\right)$. They collect PM on quartz-fiber filters. Thermal-optical analysis monitors OC charring by the change in a laser signal either reflected from or 
transmitted through a filter punch. These methods define the carbon evolving after the detected optical signal attains the value it had prior to heating as EC. All other carbon count as OC [73]. Uncertainty in thermal measurements may results from inaccurate correction for charred $\mathrm{OC}$ and catalytic oxidation of $\mathrm{BC}$ when the sample contains metals or metal oxides.

The integrating sphere method measures attenuation. A calibration curve established with commercial BC (Elftex 124, Cabot Corporation) permits conversion of the decrease in signal to $[\mathrm{BC}]$. The analysis requires homogeneous samples either from a rotating impactor, or suspensions in liquid. In the former case, the sample filter is placed at the entrance port between the light source and sphere. The sphere behaves as a diffuse detector. The change in transmission between the loaded and reference filters is interpreted as caused by absorption. In the latter case, the loaded filter is dissolved in a suitable solvent (e.g. chloroform for polycarbonate filters). The refractive indices of the solvent and most aerosols are similar. Thus, non-BC aerosols cause no enhanced light absorption even when not fully dissolved. After placement of the dissolved sample in the center of the sphere, light from the source and the light uniformly distributed within the sphere irradiate the sample. Any absorbing substance in the sample decreases the signal. In this kind of spheres, the detector is at the bottom port and a second diffuse detector is at the entrance port of the light beam. This setup also permits analysis of samples on filters [74]. Uncertainty results from the assumptions of no scattering losses and homogeneous optical filter properties.

\subsection{Acoustic Detection Method}

Photoacoustic spectrometers (PAS) draw particles into an acoustic cavity at typical flow rates of 1 liter. $\mathrm{min}^{-1}$. Here a power-modulated laser irradiates them. When particles absorb laser light, they transfer heat to the surrounding gas. Sensitive microphones detect the sound wave caused by heating and cooling. The intensity of the wave is interpreted as PM light absorption by calibration with $\mathrm{NO}_{2}$ absorption. Typical averaging times are 3 to $4 \mathrm{~s}$. Uncertainty results from gas-phase absorbers interfering with the $\mathrm{BC}$ detection. Overall uncertainty is about $5 \%$ [75]. A recent study demonstrated that the sensitivity of PAS is too coarse to capture typical $[\mathrm{BC}]$ of the high Arctic.

\subsection{Instrument Comparison and Cross-Calibration}

Due to their design the various instruments may provide different concentrations. Recommendations for calibration and inter-comparison of filter-based visible light absorption instruments can be found in [69]. Most instrument inter-comparisons took place in mid-latitude urban environments. A comparison of thermal and thermal-optical methods (TOT) using Sunset instruments, the IS method, and MAAP in Vienna, for instance, revealed $44 \%$ and $17 \%$ lower [EC] with the TOT than the mean of all observed [EC] including the TOT data; larg- 
est discrepancy occurred for large contributions of brown carbon to total carbon [76]. Mean [BC] from filter and impactor samples collected for 3 weeks analyzed with a thermal method, a thermal-optical method, the VDI method, a filter transmission method and IS method agreed with the mean [BC] from co-located aethalometer and MAAP within their standard deviations [55]. Co-located (sidewalk level in Vienna in June 1998) [BC] measurements revealed that the aethalometer provided only about $50 \%$ of the $[\mathrm{BC}]$ obtained with the IS method [55], i.e. a factor of 2 difference.

In urban environments, $[\mathrm{BC}]$ can be several orders of magnitude higher than in the Arctic. At low concentrations, a small difference among measurements can already mean a factor of 2 differences, while at high concentrations, a factor two difference requires a large difference in [BC] [77]. This means at the typical Arctic $[\mathrm{BC}]$, distinguishing between signals, noise and inter-instrument uncertainty may become challenging.

Aethalometer, thermal desorption and SPS measurements at Alert between March 2011 and December 2013 showed that typically, [EBC] was 2.7 and [EC] was 3.1 times higher than [rBC] [58]. At Zeppelin station, Norway, annual mean [BC] from aethalometer observations in 1991, and 2001-2007 [57], and an optical method on W41-filters between 1991 and 2004 [78] agreed well during overlapping times [61].

[BC] determined by COSMOS, thermal-optical measurements, and SPS laser-induced incandescence agreed within 10\% [70]. CLAP and PSAP attenuation coefficients co-measured at 17 sites agreed within $8 \%$, i.e. measurement uncertainty; CLAP and PSAP noise levels are similar within a factor of 2 [68].

Corrected TOR data provide the same OC/EC splits for most temperature protocols. For identical temperature protocol, simultaneous thermal/optical transmittance (TOT) corrections provide $30 \%$ lower [EC] than TOR; for protocols with high temperatures and short residence times, [EC] can be $70 \%-80 \%$ lower than TOR. This behavior occurs for samples dominated by anthropogenic combustion and wildfires [73]. Aethalometer derived [BC] were only $30 \%$ of those obtained by an IS method; the IS method suggested a $21 \%$ overestimation compared to a thermal method [55].

Figure 5 compares measurements from two calibrated, co-located aethalometer performed at College, Alaska. For the time shown, at $370 \mathrm{~nm},[\mathrm{BC}]$ mean, standard deviation, skewness, and kurtosis were $8.4 \pm 8.8 \mathrm{ng} \cdot \mathrm{m}^{-3}, 7.5$, and 116.8 for aethalometer 545 , and $7.7 \pm 7.5 \mathrm{ng} \cdot \mathrm{m}^{-3}, 7.2$, and 98.1 for aethalometer 361 , respectively. This means that these moments were $10 \%, 17 \%, 5 \%$ and $20 \%$ lower for 361 than 545. Measurements had a correlation coefficient of 0.909, i.e. $83 \%$ correlation. At $880 \mathrm{~nm}$, correlation was $87 \%(\mathrm{R}=0.932)$. Mean, standard deviation, skewness, and kurtosis were $15.0 \pm 16.1 \mathrm{ng} \cdot \mathrm{m}^{-3}, 5.5$, and 41.5 for aethalometer 545 , and $13.9 \pm 13.8 \mathrm{ng} \cdot \mathrm{m}^{-3}, 5.5$, and 49.1 for aethalometer 361 ; i.e. aethalometer 545 provided an $8 \%$ and $16 \%$ higher mean and standard deviation, a $15 \%$ lower kurtosis, but same skewness than aethalometer 361 . 


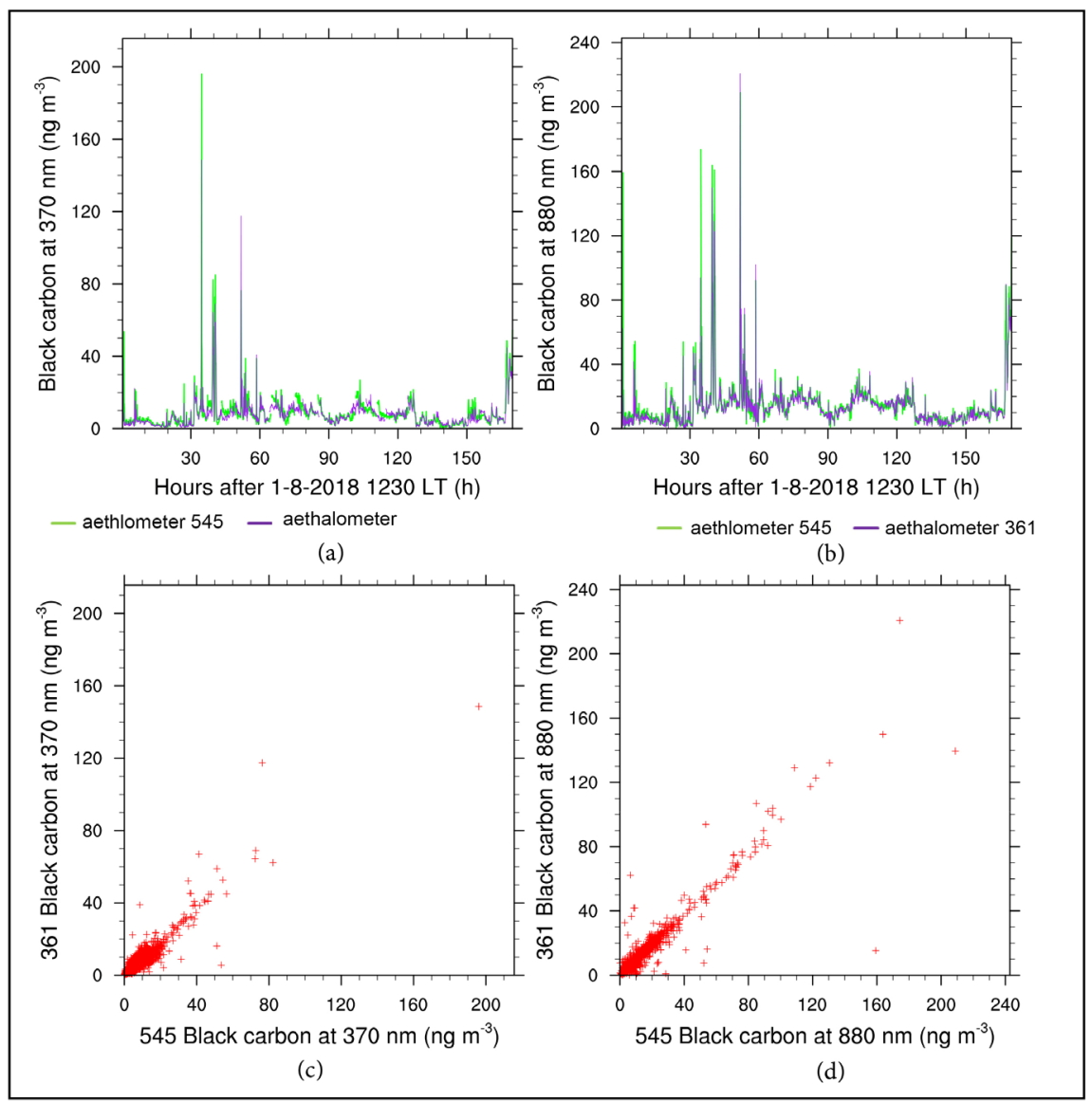

Figure 5. Comparison of [EBC] as obtained by two co-located aethalometer in College. Data shown are for 1-8-2018 1230 LT to 1-16-2018. Temporal evolution as obtained by aethalometer 361 (purple) and 545 (green) at (a) $370 \mathrm{~nm}$, (b) $880 \mathrm{~nm}$, scatter plot of [EBC] obtained from aethalometer $545 \mathrm{vs.} 361$ for (c) $370 \mathrm{~nm}$, and (d) $880 \mathrm{~nm}$.

Observations at 370 and $880 \mathrm{~nm}$ correlated $83 \%(\mathrm{R}=0.923)$ for aehalometer 545 , and $87 \%(\mathrm{R}=0.939)$ for aehalometer 361 . During the time period, $5-\mathrm{min}$ mean and maxima of $[\mathrm{BC}]_{370 \mathrm{~nm}}$ were $196.1 \mathrm{ng} \cdot \mathrm{m}^{-3}$ and $148.5 \mathrm{ng} \cdot \mathrm{m}^{-3}(24 \%$ difference) and those of $[\mathrm{BC}]_{880 \mathrm{~nm}}$ were $208.9 \mathrm{ng} \cdot \mathrm{m}^{-3}$ and $220.7 \mathrm{ng} \cdot \mathrm{m}^{-3}$ (5\% difference) for instrument 545 and 361, respectively.

Discrepancies may be due to local emissions, heterogeneous distribution of $\mathrm{BC}$ in air, discrepancies in the onset of a new measurement cycle, and aforementioned differences from one instrument to the other. Heterogeneous distributions may occur due to segregation effects [79]. The skewness, and kurtosis values hint at discrepancies from size distribution. The tails approach zero frequency more slowly than a Gaussian, i.e. there are more outliers. Once a large particle enters one device, the other device cannot pick it up and large differences occur (Figure 5).

\subsection{Normalization of Data from Various Sites}

When applied to different sites, aethalometer-correction algorithms often fail to remove the ATN-dependence from shadowing effects [80]. Values of $\sigma_{a p}$ are 
about constant in the same environment, but differ among regions. Aging of BC aerosol namely not only depends on co-emissions, but also on meteorological conditions due to temperature and/or moisture dependent reactions, transport and removal processes [6]. Unfortunately, climatological conditions in the Arctic range from temperate maritime climate along the Norwegian coast, over warm summer continental (hemiboreal), sub-arctic and boreal climates to tundra climate along the North American and Siberian coasts of the Arctic Ocean [20]. Consequently, even when measurement protocols, filters, sampling times, flow rates, and instrument types are the same, $[\mathrm{BC}]$ data from sites in different Arctic environments are not necessarily comparable due to site-dependent corrections [80].

Temporary co-location of filter-based absorption photometers (e.g. PSAP, MAAP, CLAP) can provide a site-dependent normalization factor

$$
C_{f}=\frac{\sigma_{A T N, \text { photometer }}}{\sigma_{a p, \text { photometer }}}
$$

That permits comparison of BC measurements by identical aethalometer at different sites. This factor gives how much greater the attenuation coefficient is when compared to the light absorption coefficient of the co-located filter-based absorption photometer that had been corrected for loading and scattering artifacts (see Section 3.2). This normalization avoids statistics to be concentration-weighted. Recall filter-based absorption photometers are accurate within $20 \%-30 \%$ of the true $\sigma_{a p}$.

Using data from co-located filter-based absorption photometers at Alert (Canada), Summit, Barrow (Alaska), Tiksi, Pallas (Finland), and Zeppelin (Norway) yielded a normalization factor of 3.45 for Arctic aethalometer measurements at low elevation; this factor fails for high elevation (Summit). Typically, uncertainty of $C_{f}$ exceeds uncertainty from measurement noise. At Alert, for instance, $[\mathrm{BC}]$ was determined for 1989 to 2007 using an aethalometer cross-calibrated to a two-step thermal method. Consistent with common practice, an effective attenuation coefficient of $19 \mathrm{~m}^{2} \cdot \mathrm{g}^{-1}$ and no loading corrections were used [55]. At Barrow, and Ny-Ålesund, for instance, long-term PSAP observations of light absorption coefficient $\sigma_{A T N}$ exist. However, $\sigma_{A T N}$ has been converted to $\mathrm{BC}$ mass concentration $\left([\mathrm{BC}]=\sigma_{A T N} / \sigma_{a p}\right)$ using different $\sigma_{a p}$ values [81]. During 2012-2015, COSMOS measured $\sigma_{A T N}$ at these sites. COSMOS derived $[\mathrm{BC}]$ (using a $\sigma_{a p}$ determined in previous studies) agreed within $9 \%$ with [EC] at Barrow over the 11-mon of PSAP and COSMOS co-location [81]. PSAP light absorption coefficients exceeded those of COSMOS by $22 \%$ and $43 \%$, at Barrow $\left(\mathrm{PM}_{1}\right)$ and Ny-Ålesund $\left(\mathrm{PM}_{10}\right)$, respectively [2]. COSMOS $\sigma_{A T N}$ served to derive [BC] from the PSAP $\sigma_{A T N}$ measurements made since 1998 [81].

\section{Arctic Black Carbon Observations}

\subsection{Black Carbon Vertical Profiles}

Few vertical profiles of [BC] exist. A 2-years (2011-2012) campaign with 200 
vertical profiles up to $1200 \mathrm{~m}$ above ground level from tethered balloons at Ny-Ålesund showed the following major behaviors [82]: Background conditions showed homogeneous $[\mathrm{BC}]$ profiles, while transport caused strong vertical gradients. Surface inversions and/or local emissions led to high $[\mathrm{BC}]$ close to ground. Ground-based plumes of secondary aerosol formed from local emissions of pollutants led to decreasing [BC] with height dependent on size [82].

During the Arctic Climate Change Economy and Society (ACCES) campaign, vertical profiles of $B C$ mass mixing ratios (MMR) up to $11 \mathrm{~km}$ height were derived from SP2s flown onboard of two aircrafts over Iceland, West Greenland both in 2012 and 2013, as well as Scandinavia up north to Svalbard in 2012; BC MMR were $\sim 10 \mathrm{ng} / \mathrm{kg}$ and nearly independent of height as expected given weak local sources/sinks and far distant source regions [83]. Data collected in the North American Arctic during the April and June-July 2008 Arctic Research of the Composition of the Troposphere from Aircraft and Satellites (ARCTAS) campaign also showed that transport efficiency, source region and season determined $[\mathrm{BC}]$ profiles; on average over all Arctic flights, [BC] was $107 \pm 55$ $\mathrm{ng} \cdot \mathrm{m}^{-3}$ and $9.9 \pm 5.7 \mathrm{ng} \cdot \mathrm{m}^{-3}$ in spring and summer, respectively.

\subsection{Black Carbon in the Near-Surface Atmosphere}

Arctic BC measurements are scarce. At Kevo, atmospheric [BC] were derived from weekly filter samples using optical and thermal-optical methods from 1964 to 2010. This dataset is the longest Arctic [BC] record. At the research stations Alert, Barrow, Ny-Ålesund, Summit, Nord (Greenland), Pallas, and Tiksi, data exist from long-term monitoring of $[\mathrm{BC}]$ with aethalometer. At some places, data exist from individual research projects or field campaigns. At five background sites in Finland, $[\mathrm{BC}]$ observations from MAAPs and aethalometer exist; annual mean $[\mathrm{BC}]$ was highest at Virolahti $\left(385-460 \mathrm{ng} \cdot \mathrm{m}^{-3}\right)$, followed by Hyytiälä $\left(250-370 \mathrm{ng} \cdot \mathrm{m}^{-3}\right)$, Utö $\left(230-270 \mathrm{ng} \cdot \mathrm{m}^{-3}\right)$, Puijo $\left(225-230 \mathrm{ng} \cdot \mathrm{m}^{-3}\right)$, and Pallastunturi $\left(60-70 \mathrm{ng} \cdot \mathrm{m}^{-3}\right.$ ) [84]. Typically, $\mathrm{PM}_{2.5}$ contained between 5 and $10 \% \mathrm{BC}$ with highest percentage at Virolahti located close to the Russian border.

Figure 6 summarizes mean [BC] in the sense of a climatology following [21] [85] with samples of [BC] taken for periods of different length, at different times and locations between 1969 and 2017 as found in the literature and calculated from publically available data.

At Tiksi, 2-yr observations showed distinct seasonality in [BC] (8 - 302 $\mathrm{ng} \cdot \mathrm{m}^{-3}$ ); biomass burning contributed $19 \%-73 \%$ to [BC] [58]. At Kevo, winter, spring, summer, and fall 1964-2010 mean [BC] were 339, 199, 127, and $213 \mathrm{ng} \cdot \mathrm{m}^{-3}$, respectively. Wood burning contributions to $[\mathrm{BC}]$ were marginal [61]. At the five Finish sites, spring and winter concentrations were highest due to long-range-transport of $\mathrm{BC}$, increased domestic wood burning and reduced atmospheric boundary-layer heights. Summer $[\mathrm{BC}]$ was lowest due to more effective vertical mixing. At all sites, highest $[\mathrm{BC}]$ occurred under southerly winds. Backward trajectories indicated Central and Eastern Europe as source regions. During these episodes, non-fire anthropogenic sources and open biomass 


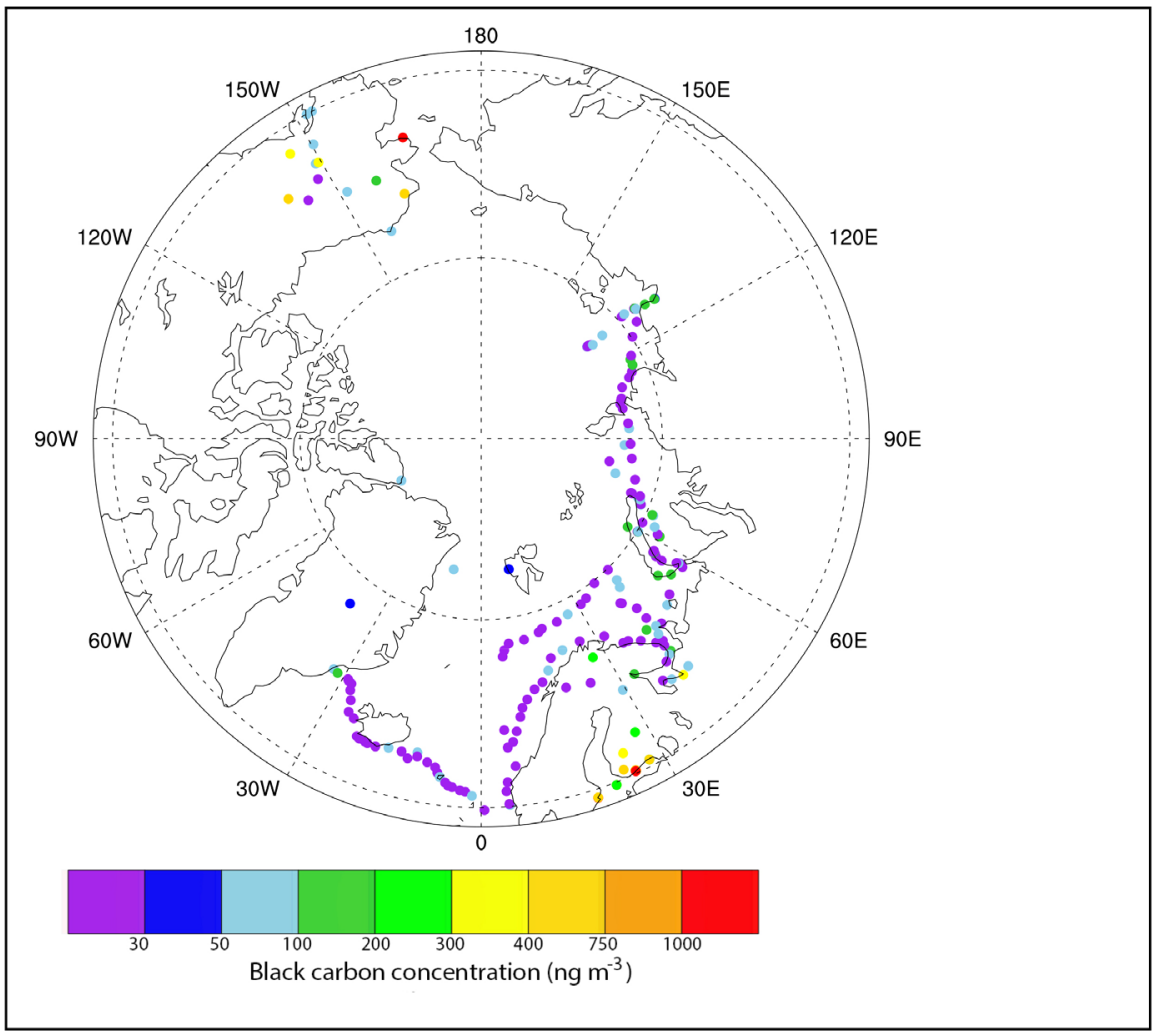

Figure 6. Composite of mean near-surface $[\mathrm{BC}]$ derived from monitoring, field campaigns or projects with various devices as reported in the literature [5] [15] [16] [57] [58] [84] [86]-[91] and EBAS. Data are means over periods of different lengths and/or years. Data of the RV Akademik Mstislav Keldysh cruises were digitized from Figure 2 in [91].

burning contributed about $62 \%$ and $36 \%$ to total [BC], respectively; biomass burning occurred most often in spring [84].

In the summers and winters from 1990 to 1992, [BC] were about 11 and 93 $\mathrm{ng} \cdot \mathrm{m}^{-3}$ at Zeppelin (475 m ASL); in summer/fall and winter/spring 1979 to 1990, [BC] was 5 and $66 \mathrm{ng} \cdot \mathrm{m}^{-3}$ at Gruvebadet $(0 \mathrm{~m} \mathrm{ASL})$, respectively. It is unclear whether the different elevation, time, changes in circulation, and/or emissions caused the quite different $[\mathrm{BC}]$; generally, measurements at Zeppelin represent the free troposphere [57]. At Zeppelin, the 1998-2007 annual mean and median $[\mathrm{BC}]$ based on thermo-optical calibration were 39 and $27 \mathrm{ng} \cdot \mathrm{m}^{-3}$, respectively.

Calculation of mean annual courses of $[\mathrm{BC}]$ revealed stronger day-to-day variation and an order of magnitude or so higher concentrations in winter than summer (Figure 7(a)). [BC] data indicated strong relationships to upwind local emissions, meteorological conditions, and climatological regimes. In the temperate maritime climate along the Norwegian Coast, for instance, frontal passages occur frequently and remove particles by scavenging; in sub-arctic climates, frequent inversions yield accumulation of particles [21]. Multi-year annual mean diurnal courses differ strongly from monthly or seasonal mean diurnal courses (Figure 7(b), Figure 7(c)). Distinct differences exist in weekend and weekday hourly means and diurnal courses (Figure $7(\mathrm{~d})$, Figure $7(\mathrm{e})$, Table 1). 


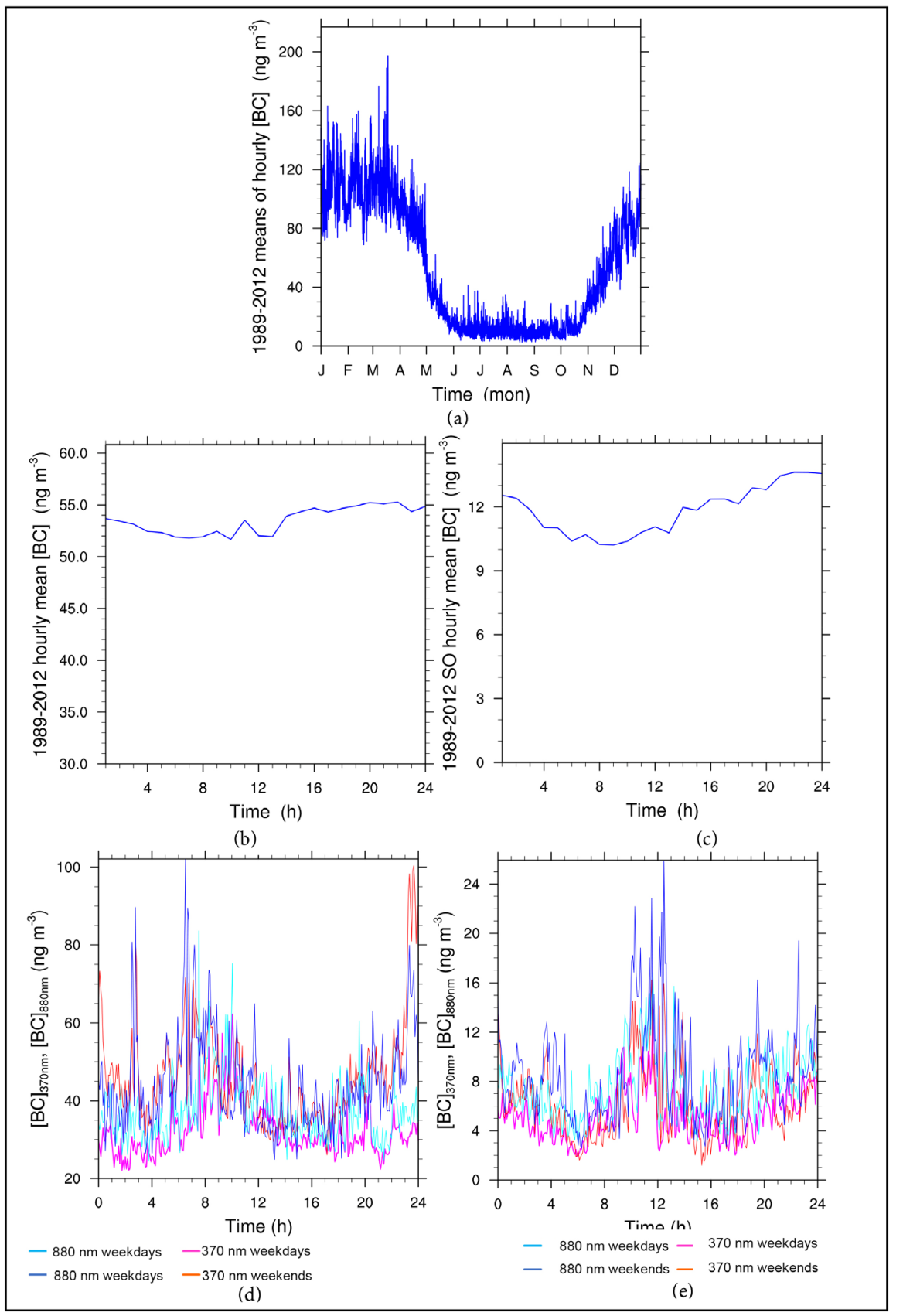

Figure 7. Examples of temporal variability as obtained from aetholometer measurements at selected sites. Alert 1989-2012 (a) Mean annual course of hourly means of [BC], (b) Mean diurnal course of hourly means of [BC], and (c) Mean September October (SO) 1989-2012 diurnal course of hourly means of [BC]. Mean annual cycles at Barrow, and Ny-Ålesund show simular behavior as Alert. Mean diurnal course of 5-min means of [BC] on weekdays and weekends both at 370 and $880 \mathrm{~nm}$ at (d) Tiksi during SO 2010, and (e) Circle, Alaska 1-23-2018 to 3-13-2018 (LT).

Figure 7(d), Figure 7(e) and Figure 4(c) also reveal that Tiksi, Circle and College have similar mean diurnal courses with higher concentrations around noon and at night than in the morning and evening. Hourly means of $[\mathrm{BC}]$ also reflect the different typical work hours in the US (9 to $5 \mathrm{LT}$ ) vs. Russia (7-4 LT). Besides 
seasonal, daily, and diurnal variability, tropical and mid-latitude long-term regimes govern Arctic [BC]. At Alert, for instance, observed [BC] was $40 \%$ higher during positive than negative phases of NAO [16].

Various studies indicated changing $[\mathrm{BC}]$. In Finland, for instance, annual mean $[\mathrm{BC}]$ decreased by $9.5 \mathrm{ng} \cdot \mathrm{m}^{-3}$ per decade between 2001 and 2007; this decrease is similar to the detection limit [57]. According to a Mann-Kendall trend test, Kevo annual mean [BC] decreased significantly by $78 \%$ with about $1.8 \%$ $\mathrm{yr}^{-1}$ from about 300 to $82 \mathrm{ng} \cdot \mathrm{m}^{-3}$ between 1970 and 2010. This decrease showed peaks around 1976-1977, 1985-1987, and 1999 that well correlated with observed nickel in air concentrations. Obviously, emissions from extensive ore smelting on the Kola Peninsula contributed notably to PM during these years [61]. At Alert, $[\mathrm{BC}]$ decreased $61 \%$ with $3.4 \% \mathrm{yr}^{-1}$ from $90 \mathrm{ng} \cdot \mathrm{m}^{-3}$ to $35 \mathrm{ng} \cdot \mathrm{m}^{-3}$ between 1989 and 2007; in the 1990s, net decreases of [BC] were about $54 \%$ and $27 \%$ at Alert and Barrow, respectively [16]. Various authors attribute the decreasing [BC] to the collapse of the economy in the former USSR [91] [92].

At Alert and Barrow, [BC] began to increase around 2000-2001 [16]. At Alert, relative contributions from Eurasia to observed $[\mathrm{BC}]$ have declined from greater than $90 \%$ to about $75 \%$; concurrently, those from North America have increased from less than $10 \%$ to nearly $25 \%$ [92].

\subsection{Black Carbon in Snow}

Nucleation-scavenging is the major process for removal of BC-containing aerosol from the atmosphere [93]. Thus, cloud and precipitation formation and ultimately precipitation affect BC's lifetime. Examining aqueous deposition for $[\mathrm{BC}]$ is uncommon.

Sampling snow to determine its BC mixing ratios started in the 1980s; it became more frequent since the 1990s. Figure 8 summarizes BC in snow mixing ratios found in the literature. In the European Arctic, 484 surface samples and 24 column samples (covering the accumulation season) were collected from 2007 to 2009. Mixing ratios were up to $88 \mathrm{ng}$ of black carbon per gram of snow (ng. $\mathrm{g}^{-1}$ ) in Scandinavia; mixing ratios decreased with increasing latitude: $11-14 \mathrm{ng} \cdot \mathrm{g}^{-1}$ in Svalbard $(74 \mathrm{~N}-81 \mathrm{~N}, 10 \mathrm{E}-34 \mathrm{E}), 7$ - $42 \mathrm{ng} \cdot \mathrm{g}^{-1}$ in Fram Strait, and $9 \mathrm{ng} \cdot \mathrm{g}^{-1}$ in Barrow [97]. In Svalbard, the 2007 median of 81 samples was $4.1 \mathrm{ng} \cdot \mathrm{g}^{-1}$ with values from 0 to $80.8 \mathrm{ng} \cdot \mathrm{g}^{-1}$. The 2010 snow samples collected over the Canada Basin and Arctic Ocean north of $65 \mathrm{~N}$ showed mean and median of $13.6 \mathrm{ng} \cdot \mathrm{g}^{-1}$ and $10.7 \mathrm{ng} \cdot \mathrm{g}^{-1}$ with mixing ratios ranging from 1.4 to $164.6 \mathrm{ng} \cdot \mathrm{g}^{-1}$ [4]. Snow samples on sea-ice collected in spring 2008-2013 between Greenland, Ellesmere Island, and the North Pole $(82 \mathrm{~N}-89 \mathrm{~N}, 0 \mathrm{~W}-100 \mathrm{~W})$ had medians of $4 \pm 3 \mathrm{ng} \cdot \mathrm{g}^{-1}$ [94]. Observed $[\mathrm{BC}]$ in snow on sea-ice decreases from Arctic coastal regions to the center of the Arctic Ocean [4] (cf. also Figure 8).

According to 36 snow samples from sites across the Arctic (Alaska, Canada, Greenland, Russia, Arctic Ocean near the North Pole) from 2007 to 2009, often more than $75 \%$ of the $\mathrm{BC}$ in snow stemmed from biomass or biofuel combustion [98]. 


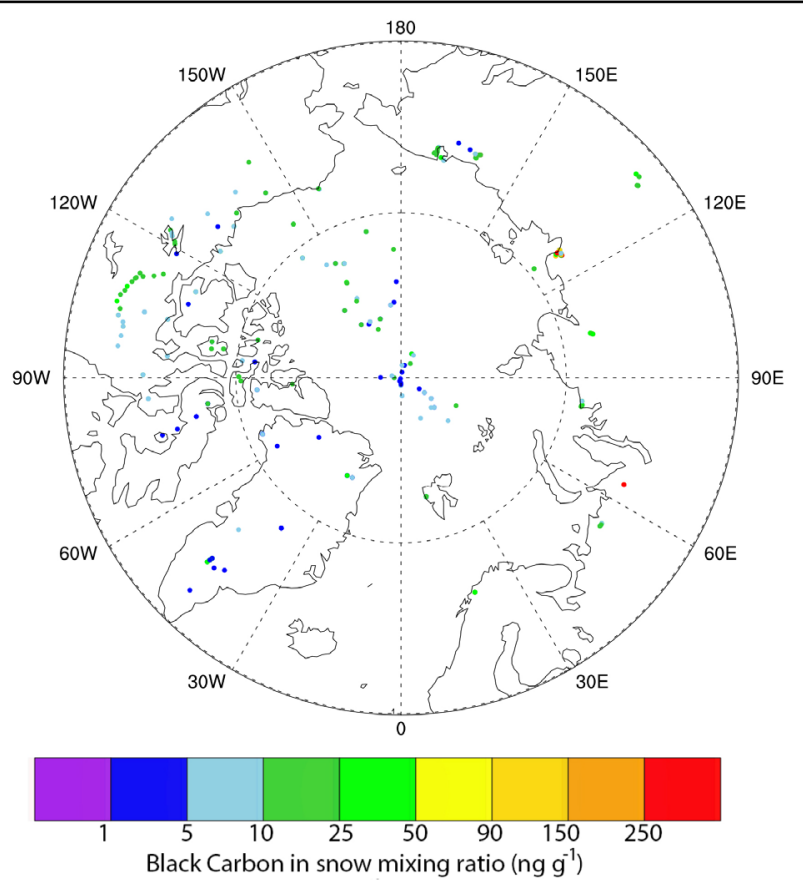

Figure 8. Composite of BC in snow mixing ratios found in [94] [95] [96].

These mixing ratios give a glimpse at the input into ecosystems after snowmelt from both sedimentation and removal by precipitation related processes. Some of the snow mass sublimates over winter. Thus, the mixing ratios found in snow samples at the end of winter, most likely exceed the ratios present in snowflakes at the time of snowfall.

Like atmospheric $[\mathrm{BC}], \mathrm{BC}$ in snow mixing ratios or $[\mathrm{BC}]$ in snow decreased over time. In Alaska, Canada, and on Arctic Ocean sea-ice, for instance, $[B C]$ in snow decreased from 15 - 30 ppb to 5 - 10 ppb within 20 years.

\section{Conclusions and Recommendations}

Meteorological (e.g. temperature, humidity, inversions, stability, snow, storms, haze, prevailing wind systems) and oceanic conditions (e.g. open water vs. sea-ice) influence $\mathrm{BC}$ emissions, $[\mathrm{BC}]$, aerosol formation, accumulation, aging and removal. Since these conditions occur with regularity in a region, we conclude that $[\mathrm{BC}]$ mitigation measures in response to the anticipated increase of Arctic shipping have to be assessed with air quality models, which need spatial and temporal emission data as input.

Our study revealed that the actual amount of $\mathrm{BC}$ emitted in the Arctic was among minor reasons, uncertain due to 1) lack or inconsistent legislature for reporting requirements among Arctic countries, and even within countries at state/province levels; 2) no common standards for stack emissions measurements, 3) classification of emission sources, and 4) spatial allocation of emissions. Consequently, emission inventories using reported data show artifacts. We conclude that standardized definitions of emission sectors, spatial allocation, 
as well as emission measurement and reporting protocols are needed when air quality models are to be deployed in the search for Arctic-wide mitigation. Enforcement of Pan-Arctic wide consistent reporting would involve (time-consuming) negotiations among the eight Arctic countries. In the meanwhile, a comparison campaign could deploy the different emissions measurement devices concurrently at the same sample of stacks to provide a basis for homogenizing existing $\mathrm{BC}$ emissions datasets.

Unfortunately, $[\mathrm{BC}]$ can only be derived by indirect methods. Consequently, existing $[\mathrm{BC}]$ data are inconsistent due to 1 ) systematic differences in measurement errors among different types of devices, 2) correction procedures, 3) different measurement protocols, 4) inlet size, 5) different QA/QC methods, and 6) methods to improve the signal-to-noise ratio. We conclude that establishing generally accepted measurement protocols, and QA/QC standards for each of the indirect methods could improve consistency of measurements performed by the same equipment. If raw data from past measurements still exist, they should be stored together with the processed data in public databases including metadata on instrument settings, changes, QA/QC, corrections applied online, as well as information on co-located instruments (if available). If possible, raw data from the past have to be re-flagged according to an agreed-upon standard. Doing so would allow scientists to create a homogenized picture of past Arctic $[\mathrm{BC}]$ as a baseline for health and other impact studies, as well as determination of trends.

\section{Acknowledgements}

We thank C.F. Cahill, G. Kramm, and the anonymous reviewers for fruitful discussion and helpful comments. The Alaska Department for Environmental Conservation supported this study with two of their aethalometer. Other data were downloaded from EBAS [99], ARM data site, EDGAR site, and GFEDv4.1 [39], [100] [101] [102] [103]. Research computational support came from the University of Alaska Fairbanks' Geophysical Institute. NEFCO and CATG provided financial support.

\section{References}

[1] Arctic-Council (2009) Arctic Marine Shipping Assessment 2009 Report. Arctic Council, Tromsa, 194.

[2] Bond, T.C., Doherty, S.J., Fahey, D.W., Forster, P.M., Berntsen, T., DeAngelo, B.J., et al. (2013) Bounding the Role of Black Carbon in the Climate System: A Scientific Assessment. Journal of Geophysical Research: Atmospheres, 118, 5380-5552. https://doi.org/10.1002/jgrd.50171

[3] Haywood, J. and Boucher, O. (2000) Estimates of the Direct and Indirect Radiative Forcing Due to Tropospheric Aerosols: A Review. Review of Geophysics, 38, 513-543. https://doi.org/10.1029/1999RG000078

[4] Dou, T.-F. and Xiao, C.-D. (2016) An Overview of Black Carbon Deposition and Its Radiative Forcing over the Arctic. Advances in Climate Change Research, 7, 
115-122. https://doi.org/10.1016/j.accre.2016.10.003

[5] Raju, M.P., Safai, P.D., Sonbawne, S.M. and Naidu, C.V. (2015) Black Carbon Radiative Forcing over the Indian Arctic Station, Himadri during the Arctic Summer of 2012. Atmospheric Research, 157, 29-36. https://doi.org/10.1016/j.atmosres.2015.01.013

[6] Seinfeld, J.H. and Pandis, S.N. (1997) Atmospheric Chemistry and Physics, from Air Pollution to Climate Change. John Wiley \& Sons, Hoboken.

[7] Mölders, N. (2011) Land-Use and Land-Cover Changes: Impact on Climate and Air Quality. Vol. 44, Springer Science \& Business Media, Berlin, 193.

[8] Moore, D., Copes, R., Fisk, R., Joy, R., Chan, K. and Brauer, M. (2006) Population Health Effects of Air Quality Changes Due to Forest Fires in British Columbia in 2003: Estimates from Physician-Visit Billing Data. Canadian Journal of Public Health, 97, 105-108.

[9] Liu, J.C., Pereira, G., Uhl, S.A., Bravo, M.A. and Bell, M.L. (2015) A Systematic Review of the Physical Health Impacts from Non-Occupational Exposure to Wildfire Smoke. Environmental Research, 136, 120-132. https://doi.org/10.1016/j.envres.2014.10.015

[10] Asikainen, A., Pärjälä, E., Jantunen, M., Tuomisto, J.T. and Sabel, E.C. (2017) Effects of Local Greenhouse Gas Abatement Strategies on Air Pollutant Emissions and on Health in Kuopio, Finland. Climate, 5, 43. https://doi.org/10.3390/cli5020043

[11] Quarato, M., De Maria, L., Franca Gatti, M., Caputi, A., Mansi, F., Lorusso, P., et al. (2017) Air Pollution and Public Health: A PRISMA-Compliant Systematic Review. Atmosphere, 8, 183. https://doi.org/10.3390/atmos8100183

[12] Liu, H.-Y., Dunea, D., Iordache, S. and Pohoata, A. (2018) A Review of Airborne Particulate Matter Effects on Young Children's Respiratory Symptoms and Diseases. Atmosphere, 9, 150. https://doi.org/10.3390/atmos9040150

[13] Janssen, N.A.H., Gerlofs-Nijland, M.E., Lanki, T., Salonen, R.O., Cassee, F., Hoek, G., et al. (2012) Health Effects of Black Carbon. In: Bohr, R., Ed., WHO. http://www.euro.who.int/_data/assets/pdf_file/0004/162535/e96541.pdf

[14] Sinkemani, R., Sinkemani, A., Li, X. and Chen, R. (2018) Risk of Cardiovascular Disease Associated with the Exposure of Particulate Matter $\left(\mathrm{PM}_{2.5}\right)$ : Review. Journal of Environmental Protection, 9, 607-618.

https://doi.org/10.4236/jep.2018.96038

[15] Segersson, D., Eneroth, K., Gidhagen, L., Johansson, C., Omstedt, G., Nylén, A.E., et al. (2017) Health Impact of $\mathrm{PM}_{10}, \mathrm{PM}_{2.5}$ and Black Carbon Exposure Due to Different Source Sectors in Stockholm, Gothenburg and Umea, Sweden. International Journal of Environmental Research and Public Health, 14, 742. https://doi.org/10.3390/ijerph14070742

[16] Sharma, S., Andrews, E., Barrie, L.A., Ogren, J.A. and Lavoué, D. (2006) Variations and Sources of the Equivalent Black Carbon in the High Arctic Revealed by Long-Term Observations at Alert and Barrow: 1989-2003. Journal of Geophysical Research: Atmospheres, 111, D14208. https://doi.org/10.1029/2005JD006581

[17] Hirdman, D., Burkhart, J.F., Sodemann, H., Eckhardt, S., Jefferson, A., Quinn, P.K., et al. (2010) Long-Term Trends of Black Carbon and Sulphate Aerosol in the Arctic: Changes in Atmospheric Transport and Source Region Emissions. Atmospheric Chemistry and Physics, 10, 9351-9368. https://doi.org/10.5194/acp-10-9351-2010

[18] Matsui, H., Kondo, Y., Moteki, N., Takegawa, N., Sahu, L.K., Zhao, Y., et al. (2011) Seasonal Variation of the Transport of Black Carbon Aerosol from the Asian Con- 
tinent to the Arctic during the Arctas Aircraft Campaign. Journal of Geophysical Research: Atmospheres, 116, D05202.

[19] Law, K.S., Stohl, A., Quinn, P.K., Brock, C.A., Burkhart, J.F., Paris, J.-D., et al. (2014) Arctic Air Pollution: New Insights from Polarcat-Ipy. Bulletin of the American Meteorological Society, 95, 1874-1895. https://doi.org/10.1175/BAMS-D-13-00017.1

[20] Kottek, M., Grieser, J., Beck, C., Rudolf, B. and Rubel, F. (2006) World Map of the Köppen-Geiger Climate Classification Updated. Meteorologische Zeitschrift, 15, 259-263. https://doi.org/10.1127/0941-2948/2006/0130

[21] Mölders, N. and Kramm, G. (2018) Climatology of Air Quality in Arctic Cities-Inventory and Assessment. Open Journal of Air Pollution, 7, 48-93. https://doi.org/10.4236/ojap.2018.71004

[22] Environment and Climate Change Canada (2016) Canada's Black Carbon Inventory. Environment and Climate Change Canada, Gatineau, 24.

[23] Mölders, N., Porter, S.E., Cahill, C.F. and Grell, G.A. (2010) Influence of Ship Emissions on Air Quality and Input of Contaminants in Southern Alaska National Parks and Wilderness Areas During the 2006 Tourist Season. Atmospheric Environment, 44, 1400-1413. https://doi.org/10.1016/j.atmosenv.2010.02.003

[24] Petzold, A., Feldpausch, P., Fritzsche, L., Minikin, A., Lauer, P., Kurok, C., et al. (2004) Particle Emissions from Ship Engines. Journal of Aerosol Science, 35, S1095-S1096.

[25] Corbett, J.J., Lack, D.A., Winebrake, J.J., Harder, S., Silberman, A.J. and Gold, M. (2010) Arctic Shipping Emissions Inventories and Future Scenarios. Atmospheric Chemistry and Physics, 10, 10271-10311. https://www.atmos-chem-phys.net/10/9689/2010/

[26] Zhan, J., Gao, Y., Li, W., Chen, L., Lin, H. and Lin, Q. (2014) Effects of Ship Emissions on Summertime Aerosols at Ny-Ålesund in the Arctic. Atmospheric Pollution Research, 5, 500-510. https://doi.org/10.5094/APR.2014.059

[27] Winther, M., Christensen, J.H., Plejdrup, M.S., Ravn, E.S., Eriksson, Ó.F. and Kristensen, H.O. (2014) Emission Inventories for Ships in the Arctic Based on Satellite Sampled AIS Data. Atmospheric Environment, 91, 1-14.

https://doi.org/10.1016/j.atmosenv.2014.03.006

[28] McCarty, J.L., Krylov, A., Prishchepov, A.V., Banach, D.M., Tyukavina, A., Potapov, P., et al. (2016) Agricultural Fires in European Russia, Belarus, and Lithuania and Their Impact on Air Quality, 2002-2012. In: Garik, G. and Volker, R., Eds., Land-Cover and Land-Use Changes in Eastern Europe after the Collapse of the Soviet Union in 1991, Springer, Berlin, 193-221.

[29] Snyder, J.M. (2007) The Polar Tourism Markets. In: Snyder, J.M. and Stonehouse, B., Eds., Prospects for Polar Tourism, CABI, Wallingford, 51-70. https://doi.org/10.1079/9781845932473.0051

[30] Berkman, P.A., Vylegzhanin, A.N. and Young, O.R. (2016) Governing the Bering Strait Region: Current Status, Emerging Issues and Future Options. Ocean Development \& International Law, 47, 186-217. https://doi.org/10.1080/00908320.2016.1159091

[31] Walsh, J.E., Fetterer, F., Scott Stewart, J. and Chapman, W.L. (2017) A Database for Depicting Arctic Sea Ice Variations Back to 1850. Geographical Review, 107, 89-107. https://doi.org/10.1111/j.1931-0846.2016.12195.x

[32] Tran, H.N.Q. and Mölders, N. (2012) Numerical Investigations on the Contribution 
of Point Source Emissions to the $\mathrm{PM}_{2.5}$ Concentrations in Fairbanks, Alaska. Air Pollution Research, 3, 199-210. https://doi.org/10.5094/APR.2012.022

[33] Roiger, A., Thomas, J.L., Schlager, H., Law, K.S., Kim, J., Schäfler, A., et al. (2014) Quantifying Emerging Local Anthropogenic Emissions in the Arctic Region: The Access Aircraft Campaign Experiment. Bulletin of the American Meteorological Society, 96, 441-460. https://doi.org/10.1175/BAMS-D-13-00169.1

[34] Pirjola, L., Paasonen, P., Pfeiffer, D., Hussein, T., Hämeri, K., Koskentalo, T., et al. (2006) Dispersion of Particles and Trace Gases nearby a City Highway: Mobile Laboratory Measurements in Finland. Atmospheric Environment, 40, 867-879. https://doi.org/10.1016/j.atmosenv.2005.10.018

[35] Robinson, M.A., Olson, M.R., Liu, Z.G. and Schauer, J.J. (2015) The Effects of Emission Control Strategies on Light Absorbing Carbon Emissions from a Modern Heavy Duty Diesel Engine. Journal of the Air \& Waste Management Association, 65, 759-766. https://doi.org/10.1080/10962247.2015.1005850

[36] Kholod, N., Evans, M., Gusev, E., Yu, S., Malyshev, V., Tretyakova, S., et al. (2016) A Methodology for Calculating Transport Emissions in Cities with Limited Traffic Data: Case Study of Diesel Particulates and Black Carbon Emissions in Murmansk. Science of the Total Environment, 547, 305-313.

https://doi.org/10.1016/j.scitotenv.2015.12.151

[37] Evans, M., Kholod, N., Kuklinski, T., Denysenko, A., Smith, S.J., Staniszewski, A., et al. (2017) Black Carbon Emissions in Russia: A Critical Review. Atmospheric Environment, 163, 9-21. https://doi.org/10.1016/j.atmosenv.2017.05.026

[38] Calvello, M., Esposito, F., Lorusso, M. and Pavese, G. (2017) A Two-Year Database of BC Measurements at the Biggest European Crude Oil Pre-Treatment Plant: A Comparison with Organic Gaseous Compounds and PM10 Loading. Atmospheric Research, 164-165, 156-166.

[39] Huang, K. and Fu, J.S. (2016) A Global Gas Flaring Black Carbon Emission Rate Dataset from 1994 to 2012. Scientific Data, 3, Article ID: 160104. https://doi.org/10.1038/sdata.2016.104

[40] Quincey, P., Butterfield, D., Green, D., Coyle, M. and Cape, J.N. (2009) An Evaluation of Measurement Methods for Organic, Elemental and Black Carbon in Ambient Air Monitoring Sites. Atmospheric Environment, 43, 5085-5091. https://doi.org/10.1016/j.atmosenv.2009.06.041

[41] Briggs, N.L. and Long, C.M. (2016) Critical Review of Black Carbon and Elemental Carbon Source Apportionment in Europe and the United States. Atmospheric Environment, 144, 409-427. https://doi.org/10.1016/j.atmosenv.2016.09.002

[42] EDGAR (2011) Emissions Database for Global Atmospheric Research. European Commission, Joint Research Center.

[43] Wang, R., Tao, S., Shen, H., Huang, Y., Chen, H., Balkanski, Y., et al. (2014) Trend in Global Black Carbon Emissions from 1960 to 2007. Environmental Science \& Technology, 48, 6780-6787. https://doi.org/10.1021/es5021422

[44] Kurokawa, J., Ohara, T., Morikawa, T., Hanayama, S., Janssens-Maenhout, G., Fukui, T., et al. (2013) Emissions of Air Pollutants and Greenhouse Gases over Asian Regions during 2000-2008: Regional Emission Inventory in Asia (REAS) Version 2. Atmospheric Chemistry and Physics, 13, 11019-11058. https://doi.org/10.5194/acp-13-11019-2013

[45] Van der Werf, G.R., Randerson, J.T., Giglio, L., van Leeuwen, T.T., Chen, Y., Rogers, B.M., et al. (2017) Global Fire Emissions Estimates during 1997-2016. Earth System Science Data, 9, 697-720. https://doi.org/10.5194/essd-9-697-2017 
[46] Wiedinmyer, C., Akagi, S.K., Yokelson, R.J., Emmons, L.K., Al-Saadi, J.A., Orlando, J.J., et al. (2011) The Fire Inventory from NCAR (FINN): A High Resolution Global Model to Estimate the Emissions from Open Burning. Geoscientific Model Development, 4, 625-641. https://doi.org/10.5194/gmd-4-625-2011

[47] Griffis, T.J., Lee, X., Baker, J.M., Russelle, M.P., Zhang, X., Venterea, R., et al. (2013) Reconciling the Differences between Top-Down and Bottom-Up Estimates of Nitrous Oxide Emissions for the U.S. Corn Belt. Global Biogeochemical Cycles, 27, 746-754. https://doi.org/10.1002/gbc.20066

[48] Amnuaylojaroen, T., Barth, M.C., Emmons, L.K., Carmichael, G.R., Kreasuwun, J., Prasitwattanaseree, S., et al. (2014) Effect of Different Emission Inventories on Modeled Ozone and Carbon Monoxide in Southeast Asia. Atmospheric Chemistry and Physics, 14, 12983-13012. https://doi.org/10.5194/acp-14-12983-2014

[49] Van der Gon, H.D., Beevers, S., D’Allura, A., Finardi, S., Honoré, C., Kuenen, J., et al. (2012) Discrepancies between Top-Down and Bottom-Up Emission Inventories of Megacities: The Causes and Relevance for Modeling Concentrations and Exposure. Springer, Dordrecht, 199-204.

[50] Timmermans, R.M.A., Denier van der Gon, H.A.C., Kuenen, J.J.P., Segers, A.J., Honoré, C., Perrussel, O., et al. (2013) Quantification of the Urban Air Pollution Increment and Its Dependency on the Use of Down-Scaled and Bottom-Up City Emission Inventories. Urban Climate, 6, 44-62. https://doi.org/10.1016/j.uclim.2013.10.004

[51] Lack, D.A. and Corbett, J.J. (2012) Black Carbon from Ships: A Review of the Effects of Ship Speed, Fuel Quality and Exhaust Gas Scrubbing. Atmospheric Chemistry and Physics, 12, 3985-4000. https://doi.org/10.5194/acp-12-3985-2012

[52] Mölders, N., Gende, S. and Pirhalla, M.A. (2013) Assessment of Cruise-Ship Activity Influences on Emissions, Air Quality, and Visibility in Glacier Bay National Park. Atmospheric Pollution Research, 4, 435-445. https://doi.org/10.5094/APR.2013.050

[53] Dickson, C. (2015) National Report by Sweden Ministry of the Environment Sweden. Ministry of the Environment Sweden, Stockholm.

[54] Environment and Climate Change Canada (2017). https://ec.gc.ca/pollution/default.asp?lang=En\&n=D521BDDF-1

[55] Hitzenberger, R., Petzold, A., Bauer, H., Ctyroky, P., Pouresmaeil, P., Laskus, L., et al. (2006) Intercomparison of Thermal and Optical Measurement Methods for Elemental Carbon and Black Carbon at an Urban Location. Environmental Science \& Technology, 40, 6377-6383. https://doi.org/10.1021/es051228v

[56] Petzold, A., Ogren, J.A., Fiebig, M., Laj, P., Li, S.M., Baltensperger, U., et al. (2013) Recommendations for Reporting "Black Carbon" Measurements. Atmospheric Chemistry and Physics, 13, 8365-8379. https://doi.org/10.5194/acp-13-8365-2013

[57] Backman, J., Schmeisser, L., Virkkula, A., Ogren, J.A., Asmi, E., Starkweather, S., et al. (2017) On Aethalometer Measurement Uncertainties and an Instrument Correction Factor for the Arctic. Atmospheric Measurements and Technology, 10, 5039-5062. https://doi.org/10.5194/amt-10-5039-2017

[58] Winiger, P., Andersson, A., Eckhardt, S., Stohl, A. and Gustafsson, Ö. (2016) The Sources of Atmospheric Black Carbon at a European Gateway to the Arctic. Nature Communications, 7, Article No. 12776. https://doi.org/10.1038/ncomms12776

[59] Petzold, A. and Schönlinner, M. (2004) Multi-Angle Absorption Photometry-A New Method for the Measurement of Aerosol Light Absorption and Atmospheric Black Carbon. Journal of Aerosol Science, 35, 421-441. 
https://doi.org/10.1016/j.jaerosci.2003.09.005

[60] Liousse, C., Cachier, H. and Jennings, S.G. (1993) Optical and Thermal Measurements of Black Carbon Aerosol Content in Different Environments: Variation of the Specific Attenuation Cross-Section, Sigma $(\Sigma)$. Atmospheric Environment. Part A. General Topics, 27, 1203-1211. https://doi.org/10.1016/0960-1686(93)90246-U

[61] Dutkiewicz, V.A., de Julio, A.M., Ahmed, T., Liang, J., Hopke, P.K, Skeire, et al. (2014) Forty-Seven Years of Weekly Atmospheric Black Carbon Measurements in the Finnish Arctic: Decrease in Black Carbon with Declining Emissions. Journal of Geophysical Research: Atmospheres, 119, 7667-7683. https://doi.org/10.1002/2014JD021790

[62] Horvath, H. (1993) Atmospheric Light Absorption-A Review. Atmospheric Environment. Part A. General Topics, 27, 293-317. https://doi.org/10.1016/0960-1686(93)90104-7

[63] Moosmüller, H., Chakrabarty, R.K. and Arnott, W.P. (2009) Aerosol Light Absorption and Its Measurement: A Review. Journal of Quantitative Spectroscopy and Radiative Transfer, 110, 844-878. https://doi.org/10.1016/j.jqsrt.2009.02.035

[64] Drinovec, L., Gregorič, A., Zotter, P., Wolf, R., Bruns, E.A., Prévôt, A.S.H., et al. (2017) The Filter-Loading Effect by Ambient Aerosols in Filter Absorption Photometers Depends on the Coating of the Sampled Particles. Atmospheric Measurement Techniques, 10, 1043-1059. https://doi.org/10.5194/amt-10-1043-2017

[65] Virkkula, A., Mäkelä, T., Hillamo, R., Yli-Tuomi, T., Hirsikko, A., Hämeri, K., et al. (2007) A Simple Procedure for Correcting Loading Effects of Aethalometer Data. Journal of the Air \& Waste Management Association, 57, 1214-1222. https://doi.org/10.3155/1047-3289.57.10.1214

[66] Holcomb, D.F. and Norberg, R.E. (1955) Nuclear Spin Relaxation in Alkali Metals. Physical Review, 98, 1074-1091. https://doi.org/10.1103/PhysRev.98.1074

[67] Hagler, G.S.W., Yelverton, T.L.B., Vedantham, R., Hansen, A.D.A. and Turner, J.R. (2011) Post-Processing Method to Reduce Noise while Preserving High Time Resolution in Aethalometer Real-Time Black Carbon Data. Aerosol and Air Quality Research, 11, 539-546. https://doi.org/10.4209/aaqr.2011.05.0055

[68] Ogren, J.A., Wendell, J., Andrews, E. and Sheridan, P.J. (2017) Continuous Light Absorption Photometer for Long-Term Studies. Atmospheric Measurement Techniques, 10, 4805-4818. https://doi.org/10.5194/amt-10-4805-2017

[69] Bond, T.C., Anderson, T.L. and Campbell, D. (1999) Calibration and Intercomparison of Filter-Based Measurements of Visible Light Absorption by Aerosols. Aerosol Science and Technology, 30, 582-600. https://doi.org/10.1080/027868299304435

[70] Kondo, Y., Sahu, L., Moteki, N., Khan, F., Takegawa, N., Liu, X., et al. (2011) Consistency and Traceability of Black Carbon Measurements Made by Laser-Induced Incandescence, Thermal-Optical Transmittance, and Filter-Based Photo-Absorption Techniques. Aerosol Science and Technology, 45, 295-312. https://doi.org/10.1080/02786826.2010.533215

[71] Müller, T., Henzing, J.S., de Leeuw, G., Wiedensohler, A., Alastuey, A., Angelov, H., et al. (2011) Characterization and Intercomparison of Aerosol Absorption Photometers: Result of Two Intercomparison Workshops. Atmospheric Measurement Techniques, 4, 245-268. https://doi.org/10.5194/amt-4-245-2011

[72] Cavalli, F., Viana, M., Yttri, K.E., Genberg, J. and Putaud, J.P. (2010) Toward a Standardised Thermal-Optical Protocol for Measuring Atmospheric Organic and Elemental Carbon: The EuSAAR Protocol. Atmospheric Measurement Techniques, 3, 79-89. https://doi.org/10.5194/amt-3-79-2010 
[73] Chow, J.C., Watson, J.G., Chen, L.W.A., Arnott, W.P., Moosmüller, H. and Fung, K. (2004) Equivalence of Elemental Carbon by Thermal/Optical Reflectance and Transmittance with Different Temperature Protocols. Environmental Science \& Technology, 38, 4414-4422. https://doi.org/10.1021/es034936u

[74] Hitzenberger, R., Dusek, U. and Berner, A. (1996) Black Carbon Measurements Using an Integrating Sphere. Journal of Geophysical Research: Atmospheres, 101, 19601-19606. https://doi.org/10.1029/95JD02412

[75] Lack, D.A., Lovejoy, E.R., Baynard, T., Pettersson, A. and Ravishankara, A.R. (2006) Aerosol Absorption Measurement Using Photoacoustic Spectroscopy: Sensitivity, Calibration, and Uncertainty Developments. Aerosol Science and Technology, 40, 697-708. https://doi.org/10.1080/02786820600803917

[76] Reisinger, P., Wonaschütz, A., Hitzenberger, R., Petzold, A., Bauer, H., Jankowski, N., et al. (2008) Intercomparison of Measurement Techniques for Black or Elemental Carbon under Urban Background Conditions in Wintertime: Influence of Biomass Combustion. Environmental Science \& Technology, 42, 884-889. https://doi.org/10.1021/es0715041

[77] Mölders, N., Tran, H.N.Q., Quinn, P., Sassen, K., Shaw, G.E. and Kramm, G. (2011) Assessment of WRF/Chem to Capture Sub-Arctic Boundary Layer Characteristics During Low Solar Irradiation Using Radiosonde, Sodar, and Station Data. Atmospheric Pollution Research, 2, 283-299. https://doi.org/10.5094/APR.2011.035

[78] Husain, L., Dutkiewicz, V.A. and Maenhaut, W. (2011) Variation in Aerosol Black Carbon in Ny-Ålesund, Spitsbergen, Norway, from 1991 to 2004. The Arctic as a Messenger for Global Processes-Climate Change and Pollution, Copenhagen.

[79] Kramm, G. and Meixner, F.X. (2000) On the Dispersion of Trace Species in the Atmospheric Boundary Layer: A Re-Formulation of the Governing Equations for the Turbulent Flow of the Compressible Atmosphere. Tellus, 52A, 500-522. https://doi.org/10.3402/tellusa.v52i5.12279

[80] Collaud Coen, M., Weingartner, E., Apituley, A., Ceburnis, D., Fierz-Schmidhauser, R., Flentje, H., et al. (2010) Minimizing Light Absorption Measurement Artifacts of the Aethalometer: Evaluation of Five Correction Algorithms. Atmospheric Measurement Techniques, 3, 457-474. https://doi.org/10.5194/amt-3-457-2010

[81] Sinha, P.R., Kondo, Y., Koike, M., Ogren, J.A., Jefferson, A., Barrett, T.E., et al. (2017) Evaluation of Ground-Based Black Carbon Measurements by Filter-Based Photometers at Two Arctic Sites. Journal of Geophysical Research: Atmospheres, 122, 3544-3572. https://doi.org/10.1002/2016JD025843

[82] Ferrero, L., Cappelletti, D., Busetto, M., Mazzola, M., Lupi, A., Lanconelli, C., et al. (2016) Vertical Profiles of Aerosol and Black Carbon in the Arctic: A Seasonal Phenomenology along 2 Years (2011-2012) of Field Campaigns. Atmospheric Chemistry and Physics, 16, 12601-12629. https://doi.org/10.5194/acp-16-12601-2016

[83] Schwarz, J.P., Weinzierl, B., Samset, B.H., Dollner, M., Heimerl, K., Markovic, M.Z., et al. (2017) Aircraft Measurements of Black Carbon Vertical Profiles Show Upper Tropospheric Variability and Stability. Geophysical Research Letters, 44, 1132-1140. https://doi.org/10.1002/2016GL071241

[84] Hyvärinen, A.P., Kolmonen, P., Kerminen, V.M., Virkkula, A., Leskinen, A., Komppula, M., et al. (2011) Aerosol Black Carbon at Five Background Measurement Sites over Finland, a Gateway to the Arctic. Atmospheric Environment, 45, 4042-4050. https://doi.org/10.1016/j.atmosenv.2011.04.026

[85] Baldasano, J.M., Valera, E. and Jiménez, P. (2003) Air Quality Data from Large Cities. The Science of the Total Environment, 307, 141-165. 
https://doi.org/10.1016/S0048-9697(02)00537-5

[86] Sisler, J.F. and Cahill, T.A. (1993) Spatial and Temporal Patterns and the Chemical Composition of the Haze and Its Impact on Visibility in Alaska. CIRA 31.

[87] Viidanoja, J., Sillanpää, M., Laakia, J., Kerminen, V.-M., Hillamo, R., Aarnio, P., et al. (2002) Organic and Black Carbon in PM2.5 and PM10: 1 Year of Data from an Urban Site in Helsinki, Finland. Atmospheric Environment, 36, 3183-3193. https://doi.org/10.1016/S1352-2310(02)00205-4

[88] Pakkanen, T.A., Mäkelä, T., Hillamo, R.E., Virtanen, A., Rönkkö, T. and Hämerti, K. (2006) Monitoring of Black Carbon and Size-Seggregated Particle Number Concentrations at 9-m and 65-m Distances from a Major Road in Helsinki. Boreal Environment Research, 11, 295-309.

[89] Enroth, J., Saarikoski, S., Niemi, J., Kousa, A., Ježek, I., Močnik, G., et al. (2016) Chemical and Physical Characterization of Traffic Particles in Four Different Highway Environments in the Helsinki Metropolitan Area. Atmospheric Chemistry Physics, 16, 5497-5512. https://doi.org/10.5194/acp-16-5497-2016

[90] Shevchenko, V., Starodymova, D., Vinogradova, A., Lisitzin, A., Makarov, V., Popova, S., et al. (2015) Elemental and Organic Carbon in Atmospheric Aerosols over the Northwestern Coast of Kandalaksha Bay of the White Sea. Doklady Earth Sciences, 461, 242-246. https://doi.org/10.1134/S1028334X1503006X

[91] Quinn, P.K., Shaw, G., Andrews, E., Dutton, E.G., Ruoho-Airola, T. and Gong, S.L. (2007) Arctic Haze: Current Trends and Knowledge Gaps. Tellus, 59B, 99-114. https://doi.org/10.1111/j.1600-0889.2006.00236.x

[92] Gong, S.L., Zhao, T.L., Sharma, S., Toom-Sauntry, D., Lavoué, D., Zhang, X.B., et al. (2010) Identification of Trends and Interannual Variability of Sulfate and Black Carbon in the Canadian High Arctic: 1981-2007. Journal of Geophysical Research: Atmospheres, 115, D07305. https://doi.org/10.1029/2009JD012943

[93] Ching, J., West, M. and Riemer, N. (2018) Quantifying Impacts of Aerosol Mixing State on Nucleation-Scavenging of Black Carbon Aerosol Particles. Atmosphere, 9, 17. https://doi.org/10.3390/atmos9010017

[94] Doherty, S.J., Dang, C., Hegg, D.A., Zhang, R. and Warren, S.G. (2014) Black Carbon and Other Light-Absorbing Particles in Snow of Central North America. Journal of Geophysical Research: Atmospheres, 119, 12,807-12,831. https://doi.org/10.1002/2014JD022350

[95] Qi, L., Li, Q., Lui, Y. and He, C. (2017) Factors Controlling Black Carbon Distribution in the Arctic. Atmospheric Chemistry and Physics, 17, 1037-1059. https://doi.org/10.5194/acp-17-1037-2017

[96] Dou, T., Xiao, C., Shindell, D.T., Liu, J., Eleftheriadis, K., Ming, J., et al. (2012) The Distribution of Snow Black Carbon Observed in the Arctic and Compared to the GISS-PUCCINI Model. Atmospheric Chemistry and Physics, 12, 7995-8007. https://doi.org/10.5194/acp-12-7995-2012

[97] Forsström, S., Isaksson, E., Skeie, R.B., Ström, J., Pedersen, C.A., Hudson, S.R., et al. (2013) Elemental Carbon Measurements in European Arctic Snow Packs. Journal of Geophysical Research: Atmospheres, 118, 13,614-13,627. https://doi.org/10.1002/2013JD019886

[98] Hegg, D.A., Clarke, A.D., Doherty, S.J. and Ström, J. (2011) Measurements of Black Carbon Aerosol Washout Ratio on Svalbard. Tellus B, 63, 891-900. https://doi.org/10.1111/j.1600-0889.2011.00577.x

[99] Tørseth, K., Aas, W., Breivik, K., Fjæraa, A.M., Fiebig, M., Hjellbrekke, A.G., et al. 
(2012) Introduction to the European Monitoring and Evaluation Programme (EMEP) and Observed Atmospheric Composition Change during 1972-2009. Atmospheric Chemistry and Physics, 12, 5447-5481.

https://doi.org/10.5194/acp-12-5447-2012

[100] ARM (2018) ARM Data Archive. US Department of Energy. https://www.arm.gov/data

[101] Commission, E. (2010) Emission Database for Global Atmospheric Research (EDGAR). Release Version 4.1. http://edgar.jrc.ec.europa.eu

[102] Randerson, J.T., van der Werf, G.R., Giglio, L., Collatz, G.J. and Kasibhatla, P.S. (2018) Global Fire Emissions Database, Version 4.1 (GFEDv4). ORNL DAAC, Oak Ridge. https://doi.org/10.3334/ORNLDAAC/1293

[103] Doherty, S.J., Warren, S.G., Grenfell, T.C., Clarke, A.D. and Brandt, R.E. (2010) Light-Absorbing Impurities in Arctic Snow. Atmospheric Chemistry and Physics, 10, 11647-11680. https://doi.org/10.5194/acp-10-11647-2010 